Argonne

\title{
Agent-Based Transportation Energy Analysis Model: Methodology and Initial Results
}

Energy Systems Division 


\begin{abstract}
About Argonne National Laboratory
Argonne is a U.S. Department of Energy laboratory managed by UChicago Argonne, LLC under contract DE-AC02-06CH11357. The Laboratory's main facility is outside Chicago,

at 9700 South Cass Avenue, Lemont, Illinois 60439. For information about Argonne

and its pioneering science and technology programs, see www.anl.gov.
\end{abstract}

\title{
DOCUMENT AVAILABILITY
}

Online Access: U.S. Department of Energy (DOE) reports produced after 1991 and a growing

number of pre-1991 documents are available free at OSTI.GOV (http://www.osti.gov/), a service

of the U.S. Dept. of Energy's Office of Scientific and Technical Information.

Reports not in digital format may be purchased by the public from the National Technical Information Service (NTIS):

U.S. Department of Commerce

National Technical Information Service

5301 Shawnee Road

Alexandria, VA 22312

www.ntis.gov

Phone: (800) 553-NTIS (6847) or (703) 605-6000

Fax: (703) 605-6900

Email: orders@ntis.gov

Reports not in digital format are available to DOE and DOE contractors from:

U.S. Department of Energy

Office of Scientific and Technical Information

P.O. Box 62

Oak Ridge, TN 37831-0062

\footnotetext{
Disclaimer

This report was prepared as an account of work sponsored by an agency of the United States Government. Neither the United States Government nor any agency thereof, nor UChicago Argonne, LLC, nor any of their employees or officers, makes any warranty, express or implied, or assumes any legal liability or responsibility for the accuracy, completeness, or usefulness of any information, apparatus, product, or process disclosed, or represents that its use would not infringe privately owned rights. Reference herein to any specific commercial product, process, or service by trade name, trademark, manufacturer, or otherwise, does not necessarily constitute or imply its endorsement, recommendation, or favoring by the United States Government or any agency thereof. The views and opinions of document authors expressed herein do not necessarily state or reflect those of the United States Government or any agency thereof, Argonne National Laboratory, or UChicago Argonne, LLC.
} 


\section{Agent-Based Transportation Energy Analysis Model: Methodology and Initial Results}

\section{By}

Marianne Mintz', Charles Macal ${ }^{2}$, Zhaomiao Guo ${ }^{1}$, Chaitanya Kaligotla², Yijiao Wang ${ }^{1}$, and Yan (Joann) Zhou ${ }^{1}$

${ }^{1}$ Energy Systems Division, Argonne National Laboratory

${ }^{2}$ Decision \& Infrastructure Sciences Division, Argonne National Laboratory

\author{
Participants \\ Lara Pierpoint \\ Theresa Christian \\ Ugi Otgonbaatar \\ Jacob Jurewicz \\ Akhilesh Ramakrishnan \\ Charles Macal \\ Marianne Mintz \\ Zhaomiao (Walter) Guo \\ Yan (Joann) Zhou \\ Jonathan Ozik \\ Josephine Wang \\ Chaitanya Kaligotla (CK)
}

Exelon Corporate Strategy
Exelon Corporate Strategy
Exelon Corporate Strategy
Exelon Corporate Strategy

Exelon Utilities, Strategy and Policy

Argonne Decision \& Infrastructure Sciences Division Northwestern-Argonne Institute for Science \& Engineering UChicago Center for Data Science \& Computation Research

Argonne Energy Systems Division

Argonne Energy Systems Division

Currently with University of Central Florida

Argonne Energy Systems Division

Argonne Global Security Sciences Division

UChicago Center for Data Science \& Computation Research

Argonne Energy Systems Division

Argonne Decision \& Infrastructure Sciences Division 
This page intentionally left blank. 


\section{Contents}

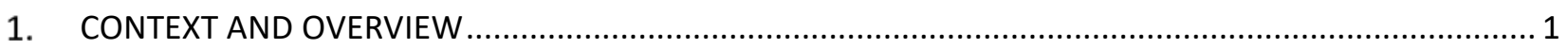

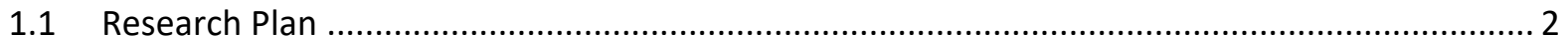

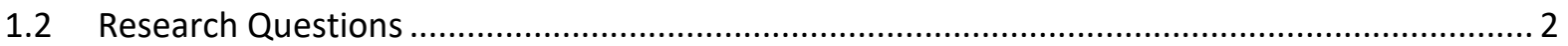

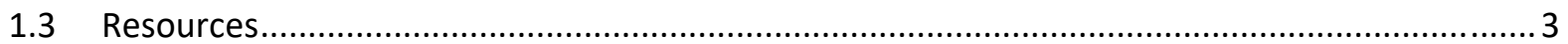

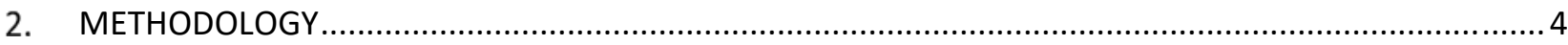

2.1 Selected Approach (Agent-Based Modeling)............................................................................ 4

2.1.1 Modeling fueling behavior (H2CAS/ZEVI Model) ................................................... 4

2.2 Applying ABM to Consumer Charging Behavior in the Chicago Metropolitan Area ................... 5

2.2.1 Existing Battery Electric Vehicles (BEVs) and charging stations ................................. 6

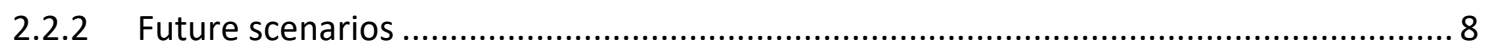

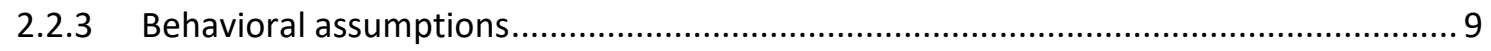

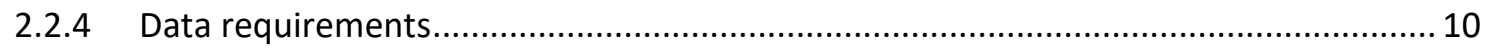

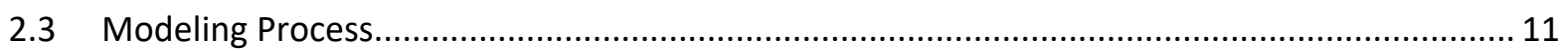

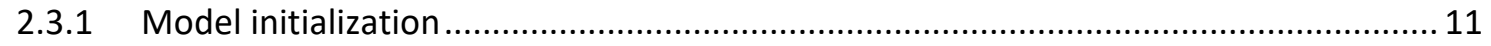

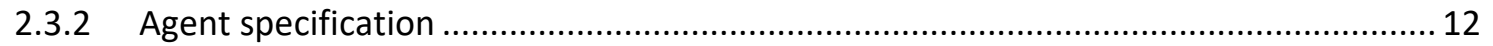

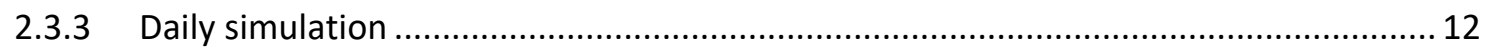

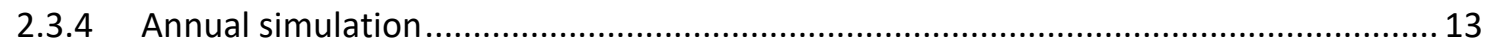

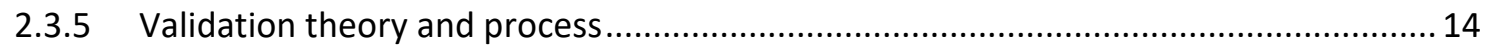

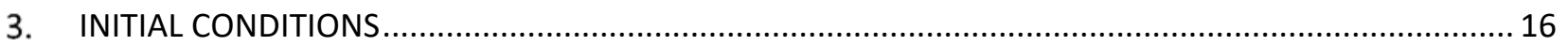

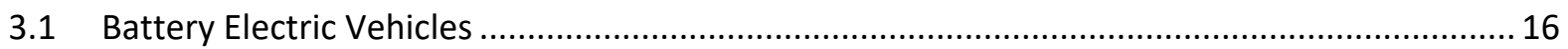

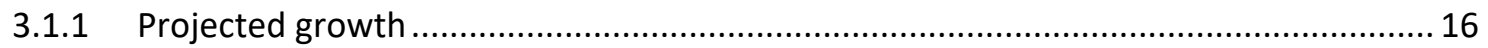

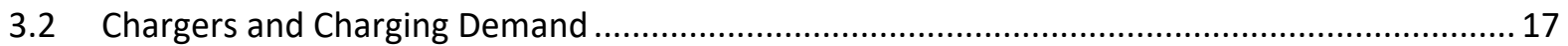

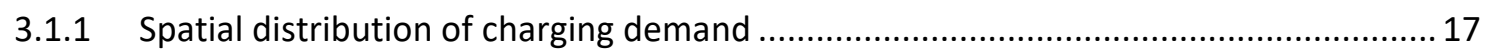

3.1.2 Temporal aspects of charging demand ............................................................... 18

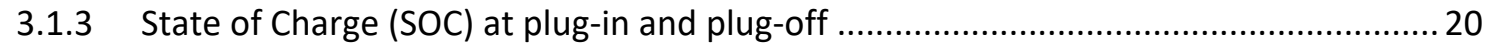

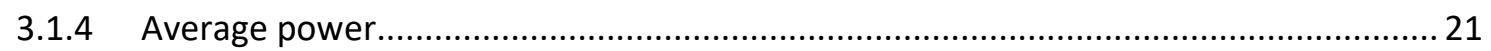

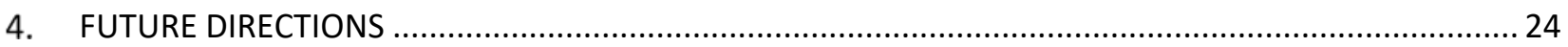

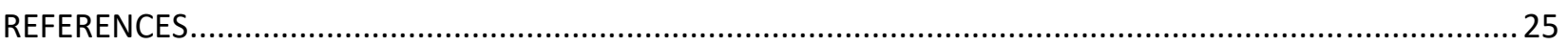

\section{Figures}

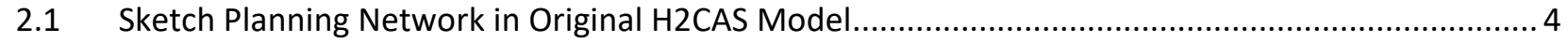

2.2 Existing FCEVs and Hydrogen Stations in the California Study Area ........................................... 5

2.3 Existing and Potential Future Hydrogen Stations as Predicted by ZEVI Model ...............................5

$2.4 \quad 2016$ BEV Registrations in Chicago Metro Area by Manufacturer and Model Year ......................... 6

2.52016 PHEV Registrations in Chicago Metro Area by Manufacturer and Model Year ........................ 6 


\section{Figures (Cont.)}

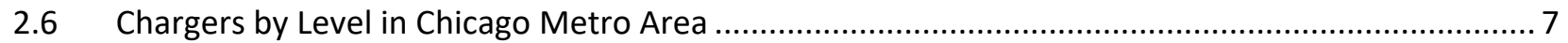

2.7 Chargers by Connector Type in Chicago Metro Area .................................................................... 7

2.8 Number of Charging Stations and BEV Registrations by State, Relative to Study Area.................... 9

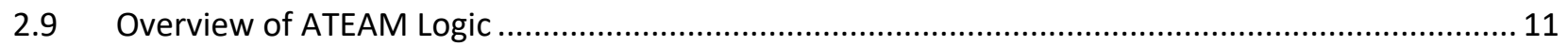

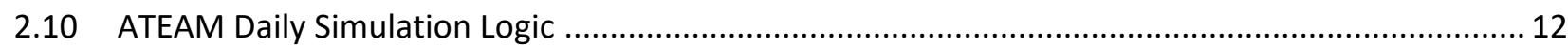

3.1 Density of BEVs and Charging Infrastructure in Study Area ................................................... 16

3.2 Estimated Chicago-Area BEV Registrations Based on U.S. BEV Registrations from EIA (2017) [1]... 17

3.3 Average Hourly Energy Demand for BEV Charging, ChargePoint Data Set....................................18

3.4 Session Plug-In Times for BEV Charging, ChargePoint Data Set.................................................. 18

3.5 Session Plug-off Times for BEV Charging, ChargePoint Data Set .................................................. 19

3.6 Average Charging Times, ChargePoint Data Set .................................................................... 19

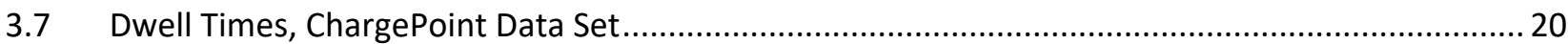

3.8 State-of-Charge at Plug-In and Plug-Off, ChargePoint Data Set ................................................... 21

3.9 Change in SOC between Plug-In and Plug-Off, ChargePoint Data Set .........................................2 21

3.10 Average Power for EV Charging in Study Area by Hour, ChargePoint Data Set............................22

3.11 Average Power for EV Charging by Hour and County, ChargePoint Data Set................................23

\section{Tables}

2.1 Number and Maximum Output by Charger Type in Chicago Metro Area ........................................ 8

2.2 Model Validation Framework and Progress to Date.................................................................... 15 


\section{CONTEXT AND OVERVIEW}

This report documents the efforts of Argonne and Exelon researchers to implement an agentbased model of charging demand and infrastructure expansion for the seven-county Chicago metropolitan area. Conducted as a project task under a broad Cooperative Research and Development Agreement (CRADA) between Argonne National Laboratory and Exelon, the project spanned a roughly 15-month time period during which Argonne and Exelon researchers developed a close working relationship. In addition to face-to-face meetings - both at the Laboratory and at Exelon's offices in Washington, DC - bi-weekly web-enabled meetings and a file-sharing folder facilitated interaction and document sharing among the project team. Team members represented a broad cross-section of skill sets and internal organization as shown in the table below.

\begin{tabular}{|c|c|}
\hline Team Member & Internal Group \\
\hline Lara Pierpoint & Exelon Corporate Strategy \\
\hline Theresa Christian & Exelon Corporate Strategy \\
\hline Ugi Otgonbaatar & Exelon Corporate Strategy \\
\hline Jacob Jurewicz & Exelon Corporate Strategy \\
\hline Akhilesh Ramakrishnan & Exelon Utilities, Strategy and Policy \\
\hline Charles Macal & $\begin{array}{l}\text { Argonne Decision \& Infrastructure Sciences Division } \\
\text { Northwestern-Argonne Institute for Science \& Engineering } \\
\text { UChicago Center for Data Science \& Computation Research }\end{array}$ \\
\hline Marianne Mintz & Argonne Energy Systems Division \\
\hline Zhaomiao (Walter) Guo & $\begin{array}{l}\text { Argonne Energy Systems Division } \\
\text { Currently with University of Central Florida }\end{array}$ \\
\hline Yan (Joann) Zhou & Argonne Energy Systems Division \\
\hline Jonathan Ozik & $\begin{array}{l}\text { Argonne Global Security Sciences Division } \\
\text { UChicago Center for Data Science \& Computation Research }\end{array}$ \\
\hline Josephine Wang & Argonne Energy Systems Division \\
\hline Chaitanya Kaligotla (CK) & Argonne Decision \& Infrastructure Sciences Division \\
\hline
\end{tabular}

In addition to these researchers, two other researchers provided key expertise to the project team before departing Argonne. These include Leah Guzowski who directed the Argonne team in the initial stages of the project and Kai Song who helped develop the user interface for the model.

This document summarizes the objectives of the study, the approach adopted to achieve those objectives and the findings obtained. In addition to this document, final deliverables produced under this project task include: 
- Interim findings summarized in the PowerPoint presentation ATEAM Methodology and Initial Results (July 18, 2018),

- Initial and calibrated versions of the Agent-based Transportation Energy Assessment Model (ATEAM),

- The ATEAM Users' Guide,

- Final report of Phase 1 research outcomes (Dec. 20, 2018), and

- Hands-on training in the use of the model.

This document contains four sections:

- Section 1 provides an overview of the effort and this report.

- Section 2 describes the simulation methodology and its application to the study area, behavioral assumptions in modeling consumer behavior with respect to charging batteryelectric vehicles (BEVs) and the model calibration process.

- Section 3 describes key conditions of the study area at the outset of the simulation, including spatial and temporal distributions of existing BEVs and charging demand.

- Section 4 highlights the next steps

\subsection{Research Plan}

The Argonne-Exelon team included researchers versed in data analytics, decision science, behavioral science, engineering, physics, urban science and transportation systems engineering. Throughout the project, researchers engaged in bi-weekly web-enabled meetings, supplemented by faceto-face meetings at the Argonne campus and Exelon's Washington D.C. office.

As described in the CRADA Task Order, the research effort focused on improving our understanding of plug-in electric vehicle (PEV) adoption and the siting of charging stations, with the goal of producing "an accessible model that provides useful answers to the question about the relationship between EV adoption and charging station buildout."

\subsection{Research Questions}

The project applied Argonne's behavioral expertise and previously developed agent-based modeling tools to Exelon's need to estimate desirable locations of future battery electric vehicle (BEV) charging and associated loads in the Chicago area. The resulting model, known as ATEAM, responds to the following four key questions raised by Exelon:

- Where should publicly available BEV chargers be located to maximize their use and aid BEV market growth?

- What is the best buildout sequence for charging infrastructure?

- What other factors affect how the BEV market will evolve spatially and temporally? 
- How will BEV adoption and the buildout of charging infrastructure impact load on the grid?

Like any new technology, the speed and trajectory of future EV market growth is unknowable. With attractive pricing vis a vis internal combustion engine (ICE) vehicles, strong public and policy support and appropriate incentive structures, growth could be robust and associated demand for EV charging could grow apace. Alternatively, high-priced BEVs coupled with cheap gasoline, weak policy support and few (if any) incentives could constrain both the BEV market and associated charging demand. By employing alternative scenarios and running multiple simulations, ATEAM enables analysts to examine a range of futures and identify commonalities among them. While each simulation yields somewhat different results, clustering occurs. The resulting insight suggests where and when EV charging infrastructure is most desirable.

\subsection{Resources}

The project relied on five primary data sources to describe current travel demand and charging behavior in the Chicago metro area and to project charging behavior through 2020:

- Alternative Fuels Data Center (AFDC): Geo-spatial data (latitude, longitude) on publicly available charging stations, number of plugs, connector type, power levels, etc. as of July 2017 [1].

- IHS Markit (formerly R.L. Polk \& Co.): BEV registrations by zip code as of December 31, 2016 [2].

- Chicago Metropolitan Agency for Planning (CMAP): Household demographics, vehicle ownership and daily personal-vehicle trips (origin/destination) by census tract and time of day based on the 2009 household travel survey [3].

- ChargePoint: Electricity delivered in charging sessions at public and private ChargePoint stations in their Chicago network by time of day, station location, charger level, length of session, state of charge (SOC) at plug-in and plug-off (for fast chargers only), etc. [4].

- U.S. Department of Energy's Energy Information Administration (EIA): 2017 forecast of BEV sales and stock in the U.S. [5].

Implemented in Java, the ATEAM model uses Repast Simphony 2.5, an interactive, versatile and user-friendly agent-based modeling platform developed and maintained by Argonne for over 15 years [6]. The above datasets provide inputs describing behavioral, economic, geographic and Social-demographic characteristics of the study area and consumer behavior. Model outputs are displayed in various formats including heat maps (produced with Arc GIS), charts, and raw data exported to other analytic tools like $R$ and Excel. 


\section{METHODOLOGY}

\subsection{Selected Approach (Agent-Based Modeling)}

Agent-based modeling ( $A B M$ ) is well- suited to addressing the research questions posed by Exelon. By modeling decisions of key stakeholders or agents, ABM captures their behavior as well as the complex interactions between them. Because agents are the key units for such models, agent-based models can evolve in complexity and robustness as additional agents and their capacity for making increasingly complex decisions are added to the underlying structure. Over the past two decades, Argonne researchers have applied agent-based models to a range of domains, advanced much of the foundational theory and practice surrounding $A B M$, and developed a modeling platform (Repast Simphony) in which to implement ABM. Two ABM efforts - known as H2CAS and ZEVI - are particularly relevant to the subject analysis.

\subsubsection{Modeling fueling behavior (H2CAS/ZEVI Model)}

Argonne began work on the Hydrogen Complex Adaptive Systems (H2CAS) model in 2005 with funding from the U.S .Department of Energy's Fuel Cell Technologies Office (FCTO) [7]. Intended to improve understanding of behavioral decision-making in the rollout of fuel cell electric vehicles (FCEVs) and their fueling infrastructure, the resulting agent-based model simulated the evolution of a hydrogen fueling network in the Los Angeles region.

The effort built upon both earlier Argonne work (discussed above) and Craig Stephan's work on complex adaptive systems while at Ford Motor Company. Led by Dr. Stephan, the H2CAS team included Matthew Mahalik, Marianne Mintz, Guenter Conzelmann and Thomas Veselka from Argonne and George Tolley and Don Jones from RCF Economic and Financial Consulting, Inc. Figure 2.1 illustrates the sketch network on which driver-agents operated FCEVs and investor agents developed hydrogen fueling stations in H2CAS simulations.

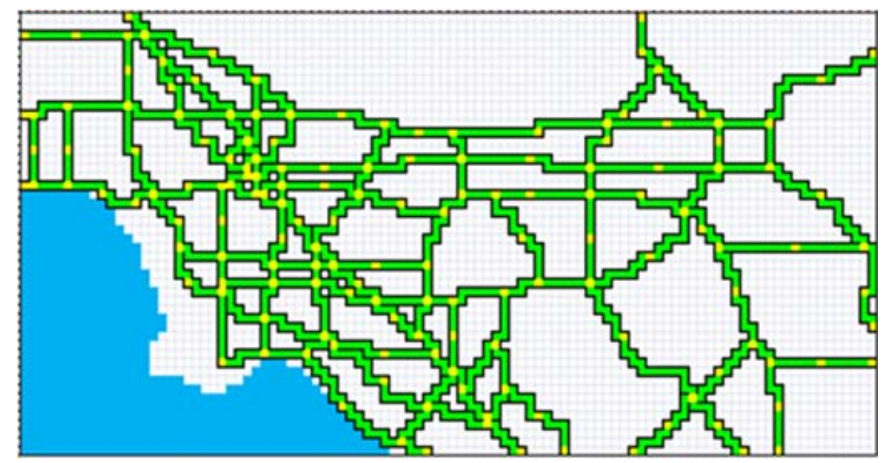

Figure 2.1 Sketch Planning Network in Original H2CAS Model

At the request of FCTO, Argonne initiated work on an update to the H2CAS model in 2017. Renamed ZEVI (Zero Emission Vehicle and Infrastructure), improvements included conversion to a 64-bit platform to improve computational ability, abandonment of a one-square mile cell structure to enhance granularity, enhanced geography and network representation, and conversion to Simphony to enable shorter time steps, more agents, more precise locations and more realistic routing. Figures 2.2 and 2.3 
show existing FCEVs and hydrogen stations in the California study area and potential future hydrogen stations as predicted by the ZEVI model.

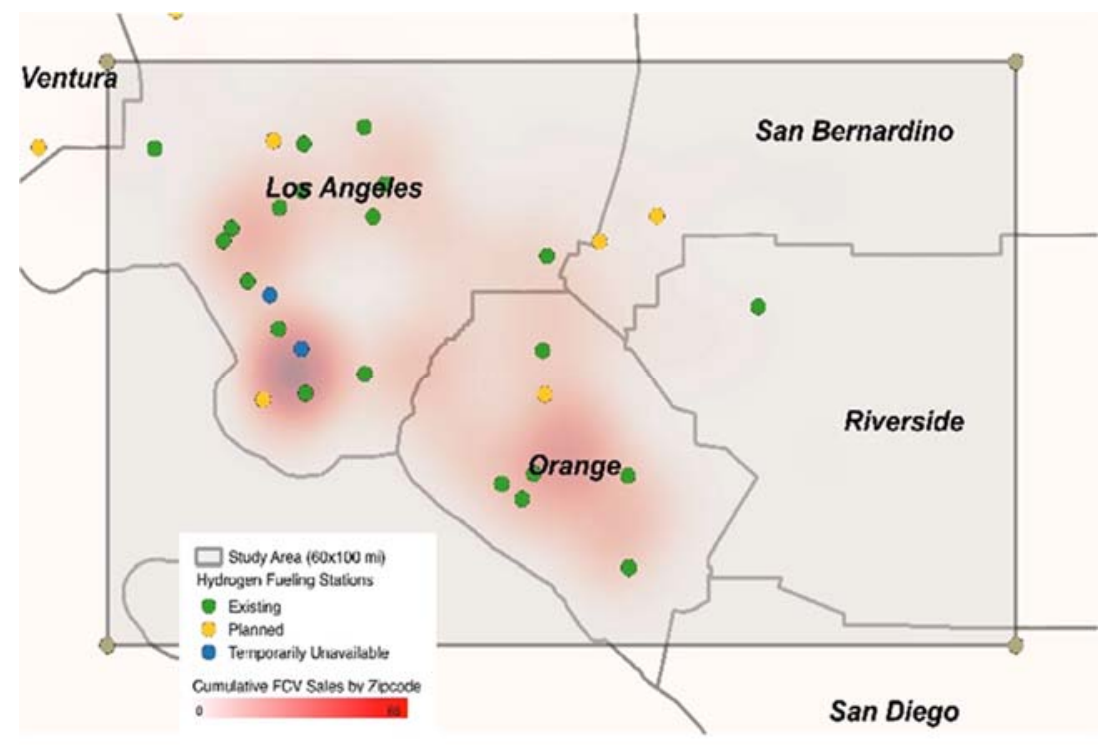

Figure 2.2 Existing FCEVs and Hydrogen Stations in the California Study Area

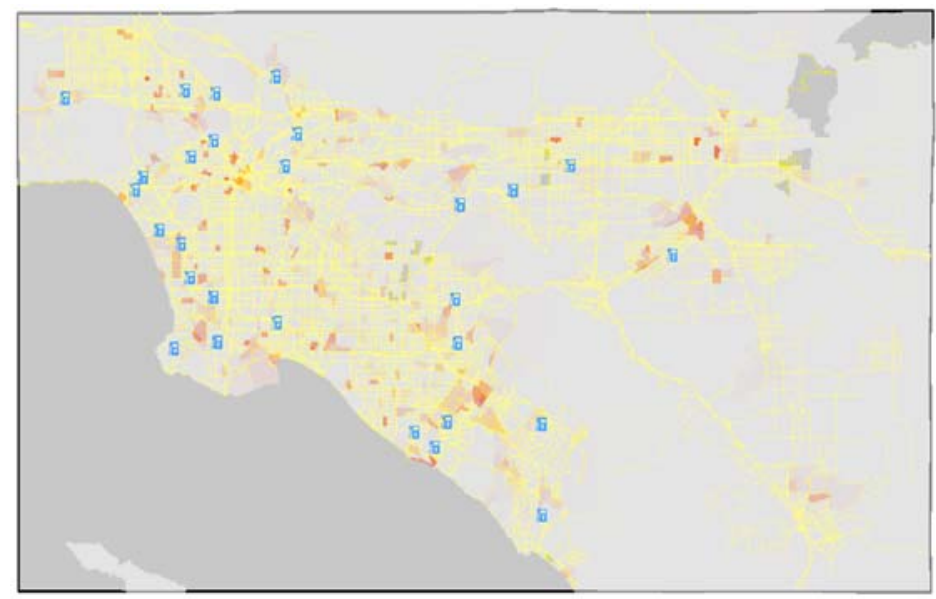

Figure 2.3 Existing and Potential Future Hydrogen Stations as Predicted by ZEVI Model

\subsection{Applying ABM to Consumer Charging Behavior in the Chicago Metropolitan Area}

The Chicago metropolitan area comprises seven counties - Cook, DuPage, Will, Lake, McHenry, Kane and Kendall - with the Chicago Metropolitan Agency for Planning (CMAP) the federally designated metropolitan planning organization for the region. CMAP conducts decennial travel surveys to compile detailed data on household travel, vehicle ownership and use, maintains extensive spatial and temporal data on household characteristics, trip origins and destinations by traffic zone, census tract, county, etc., and develops comprehensive plans addressing transportation, housing, economic development and environmental needs for the 284 communities in northeastern Illinois [3]. 


\subsubsection{Existing Battery Electric Vehicles (BEVs) and charging stations}

Few BEVs were on the road at the time of the 2008 CMAP travel survey [3]. Thus, there is no direct historical record of BEV ownership and use in the study area. Figure 2.4 shows registrations of BEVs (by make and model year) within the area at the end of 2016 [2]. ${ }^{1}$ While Tesla and Nissan dominate the BEV market, Chevrolet and Ford dominate among plug-in hybrids (which can operate in either electric or internal-combustion-engine (ICE) mode, see Figure 2.5). ${ }^{2}$

As of December 31, 2016, 3901 chargers (with 710 plugs) were in operation in the seven-county study area. Of these, 319 (82 percent) were public and 72 (18 percent) were private. Table 2.1 displays key features of these chargers while Figures 2.6 and 2.7 show the shares of the Chicagoland charging market represented by those types. Level 2 chargers with $\mathrm{J} 1772$ connectors dominate the market.

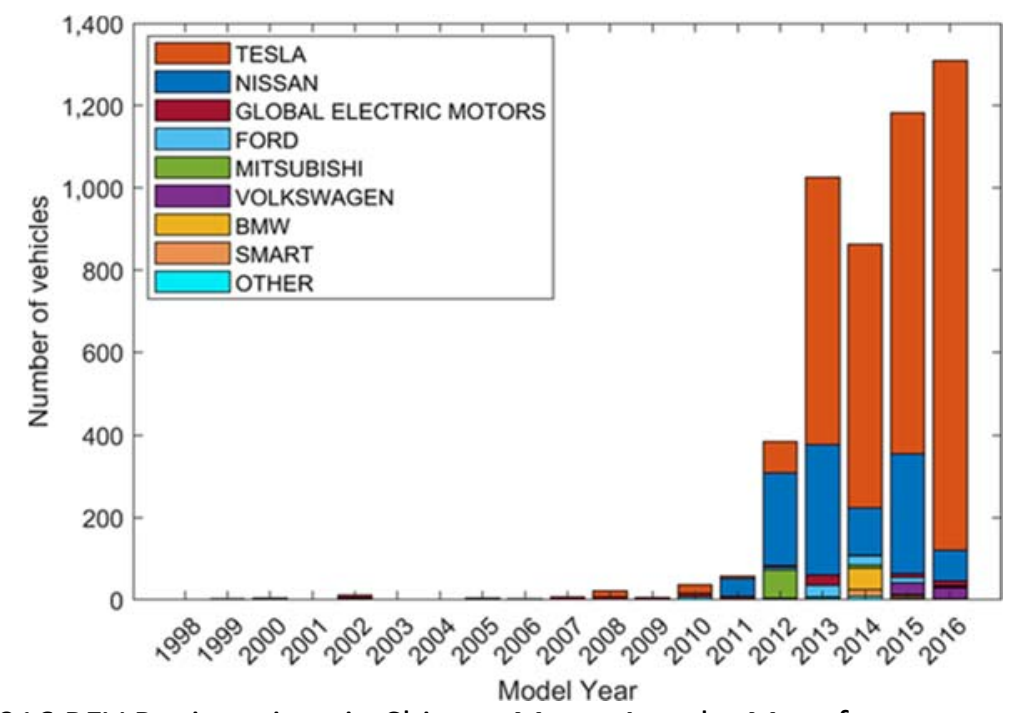

Figure 2.4 2016 BEV Registrations in Chicago Metro Area by Manufacturer and Model Year

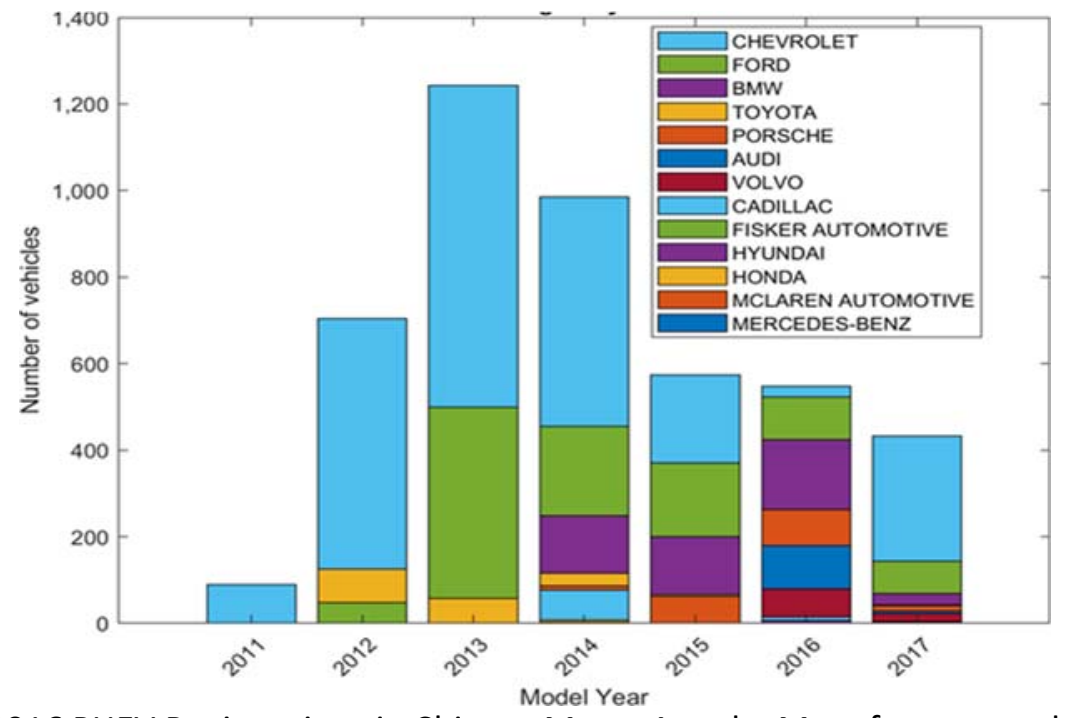

Figure 2.5 2016 PHEV Registrations in Chicago Metro Area by Manufacturer and Model Year

\footnotetext{
${ }^{1}$ Includes 2017 model year vehicles registered as of December 31, 2016.

2 Because plug-in hybrids (PHEVs) can operate as ICE vehicles (refueling at gasoline stations) they are not included in ATEAM.
} 


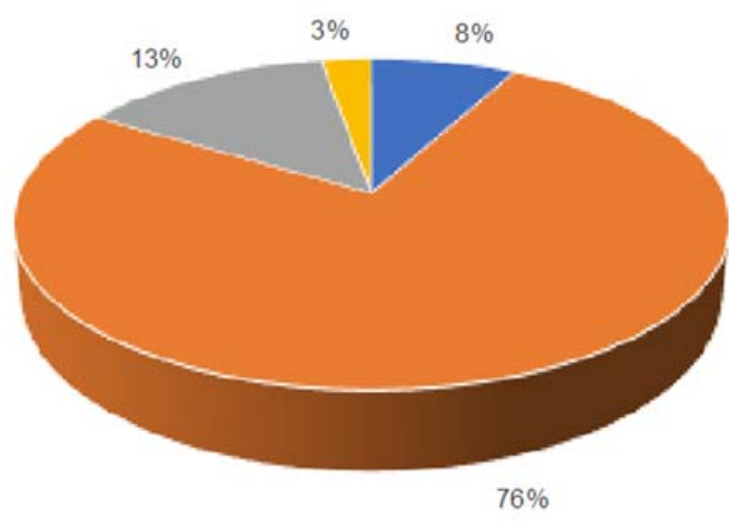

" Level 1 = Level 2 = DC Fast $=$ Tesla-Super

Figure 2.6 Chargers by Level in Chicago Metro Area

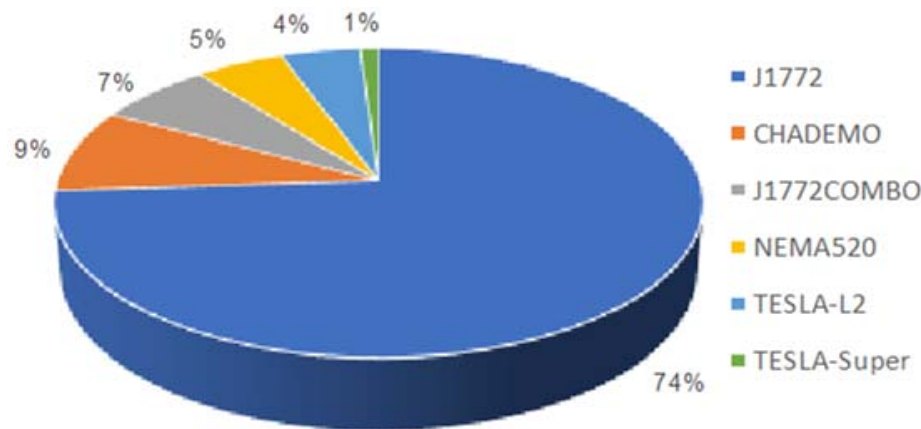

Figure 2.7 Chargers by Connector Type in Chicago Metro Area

As shown in Table 2.1 the maximum output for charging sessions recorded in the ChargePoint dataset is considerably less than the rated output as reported by the AFDC, an issue which is discussed at greater length in Appendix A. 
Table 2.1 Number and Maximum Output by Charger Type in Chicago Metro Area

\begin{tabular}{|c|c|c|c|}
\hline Charger Type & $\begin{array}{l}\text { Max Rated } \\
\text { Output }(k W)^{a}\end{array}$ & $\begin{array}{c}\text { Observed } \\
\text { Output }(k W)^{b}\end{array}$ & $\begin{array}{l}\text { Stations with } \\
\text { Charger Type }\end{array}$ \\
\hline NEMA520 & 1.9 & 1.2 & 19 \\
\hline J1772 & $3.3-19.2$ & 3.8 & 278 \\
\hline TESLA-L2 & 20 & NA & 17 \\
\hline CHADEMO & 62.5 & 19.1 & 33 \\
\hline J1772COMBO & 50 & 17.2 & 25 \\
\hline TESLA-Super & 120 & NA & 4 \\
\hline
\end{tabular}

\subsubsection{Future scenarios}

The ATEAM model can examine a range of future scenarios of BEV growth (either using exogenous forecasts or endogenously forecasting BEV adoption as a function of consumer preferences, including charging) and infrastructure buildout. The latter can reflect different preferences for charging locations, levels and frequencies; different vehicle attributes (e.g., longer or shorter range); different charging price and deployment strategies, etc. However, since this project is an initial application of the model to the BEV charging space, two relatively simple scenarios were defined to demonstrate the capability of the model vis a vis infrastructure buildout. ${ }^{3}$ The two scenarios examined for this effort were:

- "No New Investment": a business-as-usual scenario in which no additional chargers are deployed in the study area despite continued growth in BEVs; and

- "New Investment": a scenario in which additional chargers, as calculated below, are deployed where and when they satisfy the most unmet BEV charging demand.

Both scenarios utilize the same EIA forecast of national BEV sales (EIA 2017, see Figure 3.2). Chicagoland sales were assumed to represent a constant share of national BEV sales based on current adoption. The annual sales were then converted to vehicles in use (i.e., vehicle stocks) using the vehicle survival function from Argonne's VISION model [8]. Additionally, all model runs assume that BEV-owning households have access to home charging.

Empirical data reveal an inverse relationship between the density of charging stations and vehicle stocks (i.e., charging stations per 1000 vehicles) $[1,2]$. Figure 2.8 shows this relationship by state, with California represented by the data point in the far right of the graph. This highly significant relationship $\left(R^{2}=0.94\right)$ provided the basis for estimating the number of charging stations required to accommodate anticipated growth in the New Investment scenario for each year in the simulation.

\footnotetext{
${ }^{3}$ While growth in the BEV stock was of lesser interest to the current effort (since Exelon plans to replace EIA's BEV forecast with specific scenario forecasts), BEV adoption can be modeled endogenously in future efforts.
} 


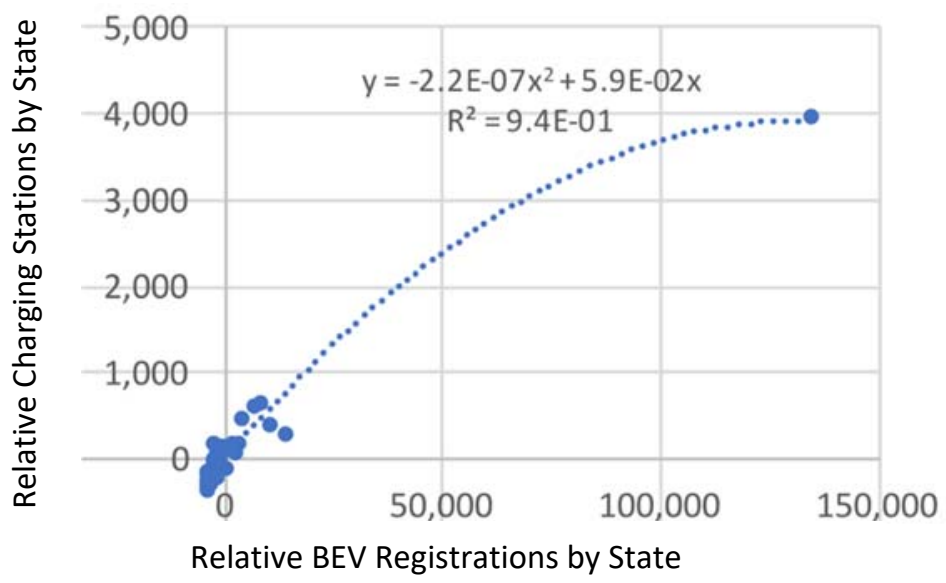

Figure 2.8 Number of Charging Stations and BEV Registrations by State, Relative to Study Area (Study Area $=0$ )

\subsubsection{Behavioral assumptions}

\subsubsection{BEV adoption}

Studies analyzing historical EV adoption show that charging availability is positively correlated with adoption [9-13]. However, this correlation varies by market segment and charger type [13]. Many studies have examined impacts of public charging infrastructure on BEV consumer acceptance in order to make projections. For example, Springel modeled the BEV market as a two-sided market with network externalities and found that BEV sales were positively related to charging station subsides [14]. Lin investigated impacts of charging deployment level on travelers' range anxiety as well as on optimized vehicle range [15]. A more recent paper by Levinson and West [16] simulated impacts of public charging on the BEV market based on the ratio of number of charging stations to the number of gasoline stations.

As discussed above, BEV adoption is an exogenous forecast in the current version of ATEAM. However, in the ATEAM simulation, the exogenous forecast is coupled to households with characteristics most like BEV owners.

The literature shows that BEV adoption is positively correlated to such Social and demographic factors as household income and education. The California Clean Vehicle Rebate program reported that roughly $34 \%$ of rebate applicants had annual income over $\$ 200,000$ (updated to April 2018) [17]. Other sources (e.g., the CA EV market update (2017) and research showing that the federal tax credit has a relatively small impact on Tesla Model $\mathrm{S}$ sales since the incentive is relatively small in terms of vehicle cost and buyer income) confirm this trend $[18,19]$. Similarly, a literature review of consumer preferences for electric vehicles (2016) showed a significant positive correlation between EV adoption and proenvironmental attitudes, income and number of vehicles in the household [20]. Moreover, a Canadian survey of potential plug-in electric vehicle buyers (2015) showed respondents had a positive and significant willingness-to-pay associated with having Level 2 charging at home [21].

In the Plug-In Electric Vehicle Multi-State Market and Charging Survey (2016), a) PEV owners had higher income, on average, b) more than half of them had post-graduate degrees, and c) $98 \%$ of them lived in detached houses [19]. Similarly, in Modeling the Spatial Distribution of Plug-In Electric Vehicle 
Owners in California GIS Scenario Planning Tool (2014) PEV owners were found to have higher incomes and their households owned more vehicles than conventional vehicle owners [22]. Therefore, in the current version of ATEAM household income, existing EV adoption and current travel experience are used to distribute EIA's forecast of BEV adoption.

\subsubsection{Spatial and temporal distribution of charging demand}

An important charging behavior is when and where BEV drivers choose to charge. Most existing models rely on scenarios and exogenous travel patterns due to the lack of empirical data on charging and use. Data on "revealed preferences" have been limited and unable to explain why drivers behave as they do. Plugged In: How Americans Charge Their Electric Vehicles (2015) shows 1) a majority of charging $(80 \%)$ is at home and work, 2 ) charging begins with $20-80 \%$ battery state of charge (SOC), and 3) many DC fast chargers experience heavy use to support both in-town and inter-city driving [23]. At the same time, a relatively small number of public $L 2$ public charging sites saw consistently high use. Moreover, this study concluded that factors determining the popularity of an individual public charging station are largely community-specific. Another study, evaluating EV charging impact and customers charging behavior (2014) found that $84 \%$ of charging sessions at public retail locations lasted less than 2 hours [24].

Therefore, in the current version of ATEAM, driver-agents prefer fast chargers (when available) and to charge when battery SOC falls below a pre-defined SOC threshold. When battery SOC is above that threshold, the driver-agent plugs-in only at home. The pre-defined plug-in SOC and plug-off SOC are calibrated by real-world charging behavior observed through ChargePoint data. Details are contained in Section 3.2.3.

Most studies evaluating the public charging infrastructure needed to support growing BEV demand, formulate node- or flow-based facility location network models to mathematically demonstrate the infrastructure requirement [25-27]. These studies assume either that the BEV will only charge at the trip destination or that the BEV will charge on route, and then calibrate the model using real-world charging data, if available. ATEAM assumes driver-agents prefer to charge their BEVs at or close to their trip destination.

\subsubsection{BEV travel}

BEV travel is directly related to where and when BEVs are charged. A few studies have analyzed travel survey data or actual travel patterns (e.g. GPS data) of conventional vehicles and examined the feasibility of replacing the conventional fleet with BEVs, assuming the same travel patterns [26-30]. Such an approach requires major assumptions about charging behavior including frequency and location. Some studies have modeled vehicle idling time as potential charging events, or modeled only home charging once a day. In terms of daily and annual travel, the 2017 National Household Travel Surveys showed a statistically significant reduction in BEV annual mileage as compared to a conventional vehicle [31]. ATEAM assumes the BEV has the same travel pattern as a conventional vehicle.

\subsubsection{Data requirements}

The key data required to simulate charging behavior and the buildout of charging infrastructure are actual charging episodes by BEV users in the study area. Since ChargePoint accounts for over 70 percent of the Chicagoland public charging market [1], a 100\% sample of ChargePoint charging sessions 
was acquired for this effort. These data pertained to all charging events at ChargePoint stations from August 1, 2017 through July 31, 2018. While details for many of these stations are available on the AFDC website, approximately $58 \%$ are privately owned/operated stations not contained on the AFDC. While these 381 stations are not explicitly modeled in ATEAM, the behavior of BEV drivers utilizing them is included in the various data summaries and comparisons contained in this document.

\subsection{Modeling Process}

As discussed above, ATEAM is an agent-based model. In this, its initial application, it simulates the buildout of charging infrastructure. As shown in Figure 2.9, the model has four main components: model initialization, agent specification, daily simulation, and annual simulation. Descriptions of each are found below as well as in the Users' Guide.

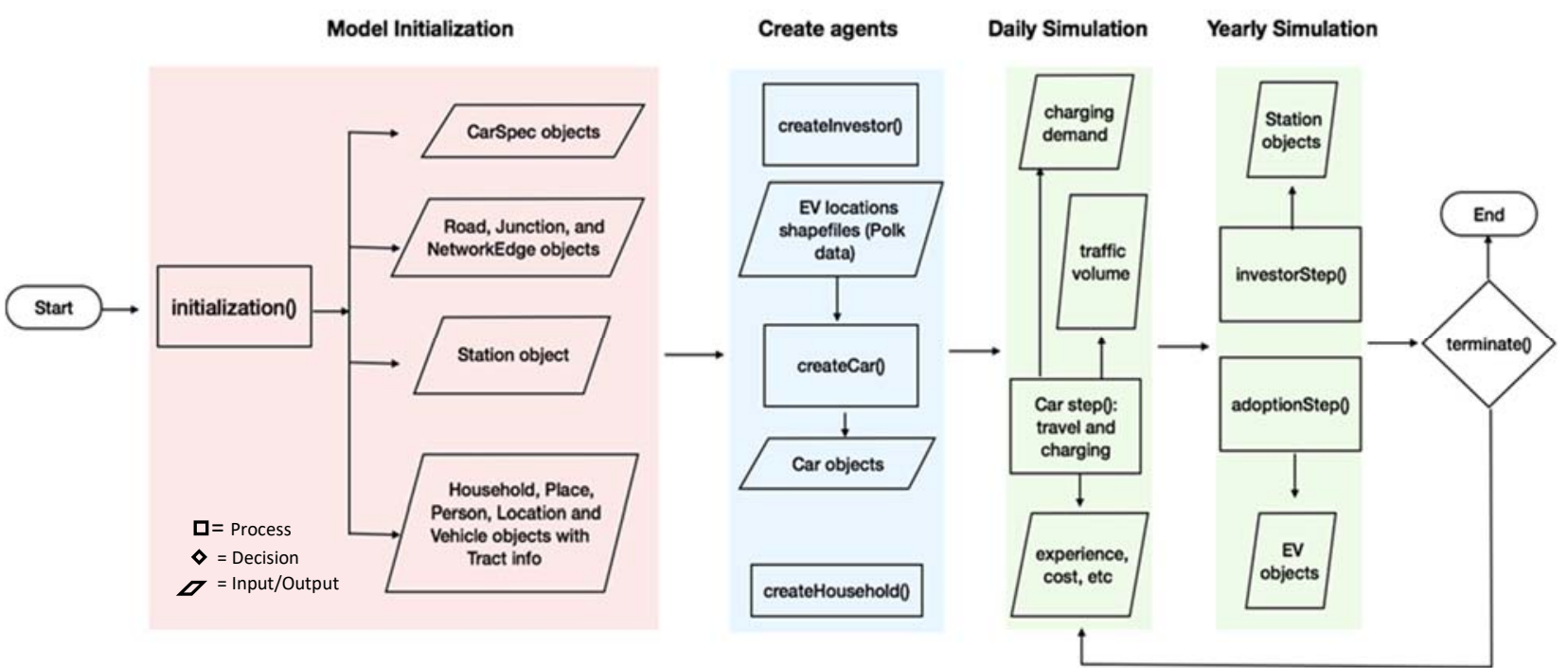

Figure 2.9 Overview of ATEAM Logic

\subsubsection{Model initialization}

In the model initialization module, datasets are integrated to a common geography, thereby establishing the simulation environment. These data sets include specifications of vehicles, characteristics of the existing transportation network and charging infrastructures, household characteristics and travel survey data. Since individual data sets may differ in geospatial resolution, this module preprocesses them to ensure compatibility. Data preprocessing strategies include:

- Initial BEV locations, which are randomly generated within each zip code based on historic BEV registrations.

- Locations of households and travel origins and destinations, which are randomly assigned in census tracts, based on CMAP travel tracker survey.

- $\quad$ BEVs associated with households, which are based on geospatial proximity.

- BEV specifications (e.g. make, model, year), which are randomly assigned within the study area based on historic market shares. 


\subsubsection{Agent specification}

To capture the interaction between EV adoption, travel, charging, and the evolution of charging infrastructure, the model incorporates three types of agents or stakeholders: individuals (or travelers), households and investors. Individuals decide on travel routes, charging times and locations, and the level and duration of charging episodes. Vehicle adoption decisions are made by households based on their Social-demographic characteristics and prior knowledge/experience with EVs. Investors decide on the location and size of new charging infrastructure depending on their own objectives (e.g. to promote EV adoption, to gain market share, to attract traffic to their other business, or simply to maximize charging profit). See Section 2.2 for additional discussion of key behavioral assumptions.

\subsubsection{Daily simulation}

In ATEAM, two interrelated simulation modules operate at different time scales and time steps. In the daily simulation module, individuals follow a daily travel routine and make routing and charging decisions at 15-minute time steps. Figure 2.10 illustrates the key decisions and logic in the daily simulation module in which all the BEVs registered in our study area (e.g. 3,589 in 2016 and 11,177 in 2020) are simulated for one representative day in each year. ${ }^{4}$

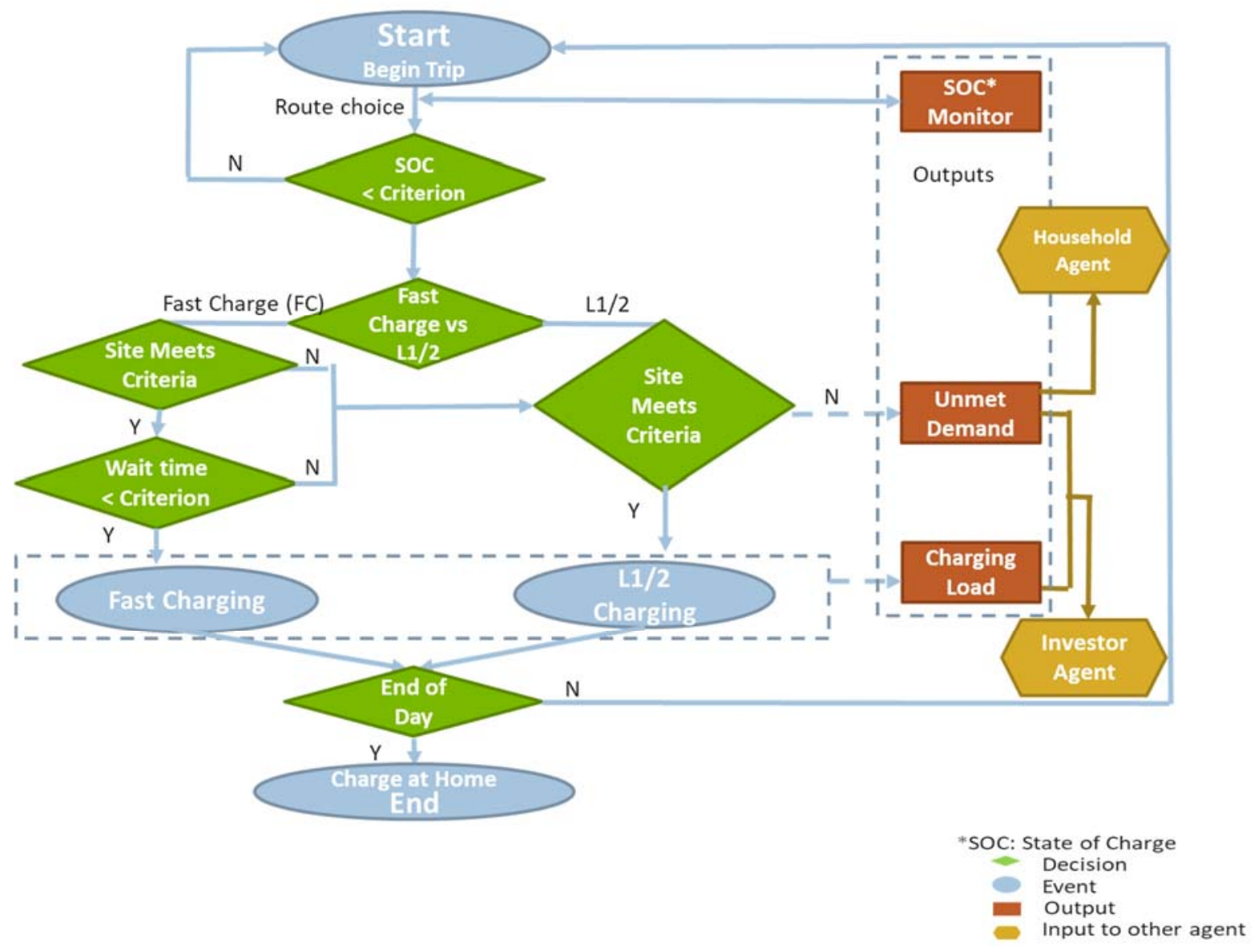

Figure 2.10 ATEAM Daily Simulation Logic

\footnotetext{
${ }^{4}$ In the future, multiple days (e.g. weekdays and weekends) could be simulated if more travel behavior data become available.
} 
Agents make three key decisions during the daily simulation: route selection, charging, and charger selection. The decision rules behind these decisions depend on agent preferences and scenarios. The assumptions used in the current model are as follows:

- Whether to charge: Agents look for chargers when their state-of-charge (SOC) falls below a percentage of battery capacity. In the uncalibrated version of the model, all driver-agents have the same SOC threshold. In the calibrated version, the distribution of SOC at plug-in (extracted from ChargePoint data) is used to randomly assign charging thresholds.

- Route selection: Agents choose the route with the shortest travel time;

- Charger selection: Agents only select chargers within one mile of their travel destination. In addition, agents prefer higher speed chargers (if available) over lower speed ones, and closer chargers over more distant ones. If drivers cannot locate a charger, they nonetheless continue their daily travel itinerary resulting in additional incomplete trips and unmet charging demand both of which are monitored to inform later investor decisions. Theoretically, SOC can fall below zero in the course of unmade trips.

Note that as more data become available, these assumptions/parameters could be adjusted. For example, EV drivers may prefer routes with more charging opportunities to reduce range anxiety; or EV drivers may start looking for chargers along their route and detour to charging stations (if necessary). Alternatively, locational differences in charging prices may come into play, affecting charger selection.

\subsubsection{Annual simulation}

In the annual simulation module, households and investors make vehicle adoption and infrastructure investment decisions, respectively. Different rules can be implemented to reflect different objectives and/or personalities of these decision makers. As a starting point, we define two important measures to guide long-term decision-making:

- Unmet charging episodes: How many times agents who are looking for a charger are unable to find one;

- Incomplete daily travel: How many trips are not made because the battery SOC falls below the driver's minimum and a charger cannot be found.

The variable "unmet charging episodes" identifies locations where potential investment could attract sufficient charging demand, while the variable "incomplete daily travel" is an important factor for households to consider when evaluating their EV driving experience. In the current version of the model, households choose EVs based on their household income, existing EV adoption and current travel experience (i.e. little or no incomplete daily travel) and investors survey spatial areas and consider current unmet charging episodes in deciding whether to supply new charging facilities in the following year.

In the future, vehicle adoption could be based on household members' travel and charging experiences. Likewise, investors could have different objectives affecting their choice of when and where to invest in charging facilities. For example, they could opt for maximum charging coverage (e.g. governments), they could seek to attract additional traffic to companion businesses (e.g. supermarkets), 
or they could simply try to maximize profits (e.g. charging service providers), minimize grid impacts, or provide grid ancillary services (e.g. utility companies).

Information between daily and annual simulations is shared and synchronized. To keep the growth rate of total EVs in the study area (i.e., the seven-county Chicago metro area) consistent with the national growth trend, the annual module is calibrated to the EV growth rate in EIA's 2017 Annual Energy Outlook [5], assuming Chicagoland maintains a constant share (see 3.2.1 for additional discussion). Alternatively, the user can define an EV growth rate as discussed in the ATEAM Users' Guide.

\subsubsection{Validation theory and process}

Model validation is a scientific discipline in its own right with a rich tradition and welldocumented procedures. Traditional model validation as practiced in the physical sciences [32-33] and managerial sciences [34-37] consists of systematically comparing simulation results to data obtained from the real world. For many systems (including systems that do not currently exist or that are not accessible to investigators) and, more generally, for systems which cannot be subjected to controlled experiments, it is not possible to validate a model by such a comparison. Alternative methods must be used to establish credibility, which in this case is confidence that the model's results are accurate to the degree required for the intended purpose of the model. Thus, validation immediately touches on the relationship between modeling and its purpose. The purpose of ATEAM is not to predict the future, but rather to provide insights into the plausible futures that may result from EV adoption and infrastructure rollout, based on plausible model assumptions.

Notwithstanding the existence of formal validation procedures, it is widely accepted in the modeling community that the truth of any computational model (or theory for that matter) cannot be established through any series of tests [38]. All that can be established is whether a model is "invalid." Nevertheless, the validation process increases confidence in a model (pseudo-validation) if more and more tests are unable to invalidate the model and its results, thus obtaining a degree of credibility for the model.

Since agent-based models and simulation (ABMS) are built from the "ground-up" (i.e., they consist of many individual agents), an added challenge is validating the models of individual agents (i.e., agent behaviors). For example, do agent interactions conform to observed activity patterns? Given the recent emergence of agent-based modeling relative to more traditional types of modeling, much ABMS validation can be described as ad hoc. However, there are some agent-based modeling sub-communities with emerging validation standards. Boero and Squazzoni [39] introduce a taxonomy of agent-based models, breaking them into three broad groups, and discuss validation methods appropriate to each group. One example is the work by Moss and Edmonds [40], where they use stakeholder input and domain experts to iteratively validate the micro (agent behavior and interaction) and macro (aggregate time-series output) aspects of their model. Another area of research is model-to-model or "docking" validation. Hales et al. [41] review a number of model-to-model validation studies. However, validating the many parameters commonly found in agent models can be prohibitively computationally expensive. Sallans et al. [42] present an efficient parameter space sampling method that they use to validate parameters used in their agent-based economic model.

Within this context we can apply six kinds of validation tests to ATEAM, as enumerated in Table 2.2. The first kind focuses on validating the data that goes into the model, as data lacking credibility 
will immediately invalidate a model's results and destroy its credibility. As discussed briefly in Section 3.2 and elaborated upon in Appendix A, data validation has been a major focus of this effort as opposed to a post-hoc or add-on activity. ${ }^{5}$ We acquired proprietary ChargePoint data and embarked on an extensive cleanup/checking process involving identification of inconsistencies, comparisons to public data sources and visualization. As part of this effort we compared calibrated and uncalibrated model results and plan to engage modeling experts for peer review of the methodology and subject matter experts for review of initial results.

Table 2.2 Model Validation Framework and Progress to Date

\begin{tabular}{|c|c|c|}
\hline Test & Application or Process & $\begin{array}{l}\text { Progress to Date } \\
X=\text { Completed } \\
(\mathrm{X})=\text { Planned }\end{array}$ \\
\hline 1. Data validation & $\begin{array}{l}\text { - Data gaps and inconsistencies } \\
\text { - } \text { Data currency } \\
\text { - } \\
\text { - } \\
\text { - Proprird-party data verification data } \\
\text { - } \text { Data visualization }\end{array}$ & $\begin{array}{l}X \\
X \\
X \text { partial } \\
X \\
X \text { partial }\end{array}$ \\
\hline $\begin{array}{l}\text { 2. Subject matter expert (SME) } \\
\text { judgment }\end{array}$ & $\begin{array}{ll}- & \text { Developer SMES } \\
- & \text { Independent SMEs } \\
- & \text { Participatory simulation }\end{array}$ & $\begin{array}{l}(X) \\
(X)\end{array}$ \\
\hline $\begin{array}{l}\text { 3. Model-to-model } \\
\text { comparison }\end{array}$ & - Model docking and equivalence testing & NA \\
\hline $\begin{array}{l}\text { 4. Critical test cases and key } \\
\text { indicator identification }\end{array}$ & & $(\mathrm{X})$ \\
\hline $\begin{array}{l}\text { 5. Comprehensive model } \\
\text { execution testing }\end{array}$ & $\begin{array}{l}\text { - } \text { Parameter space sweeps } \\
-\quad \text { Agent behavior and strategy space } \\
\text { exploration }\end{array}$ & $\begin{array}{l}(X) \\
(X)\end{array}$ \\
\hline $\begin{array}{l}\text { 6. Intentional invalidation } \\
\text { exercises }\end{array}$ & & NA \\
\hline
\end{tabular}

The third and sixth type of validation test, model-to-model comparisons (including model docking) and intentional invalidation are unlikely to assist in validating ATEAM as, to our knowledge, there are no comparable models or standard techniques for such efforts. However, the fourth and fifth types listed in Table 2.2 are promising. Identifying critical test cases and key indicators via uncertainty analysis or parameter sweeps, is highly desirable. This could include a variation on parameter sweeping over the space of possible model outputs known as "robust analysis." Lempert, Popper and Bankes [43] propose such a framework to reduce uncertainty for decision-making. Uncertainty analyses conducted with several Argonne models, including GREET and VISION, also provide a useful framework for such an effort.

\footnotetext{
${ }^{5}$ For additional discussion of data validation see Macal and North [2005] where it is applied to electric power markets.
} 


\section{INITIAL CONDITIONS}

The density of BEVs and the charging infrastructure to support them vary substantially across the study area. Although most BEV drivers charge their vehicles at home, charging stations are increasingly available at workplaces, retail centers and other locations where vehicles are parked for extended periods.

\subsection{Battery Electric Vehicles}

The stock of BEVs is currently concentrated in a wide band along the lakefront from Chicago to the southeastern edge of Lake County, in a pocket along the border of DuPage and Cook counties and in several smaller clusters in Cook, Lake, DuPage and Will counties. There are few BEVs registered in the outer suburbs, especially in McHenry and Kendall counties and in the southern portions of Will county. The shaded areas in Figure 3.1, showing BEVs per square mile, illustrate this pattern. The dots in Figure 3.1 show a similar concentration of charging stations along the lakefront but far less concentration outside Chicago where BEVs are likely to have access to home charging.

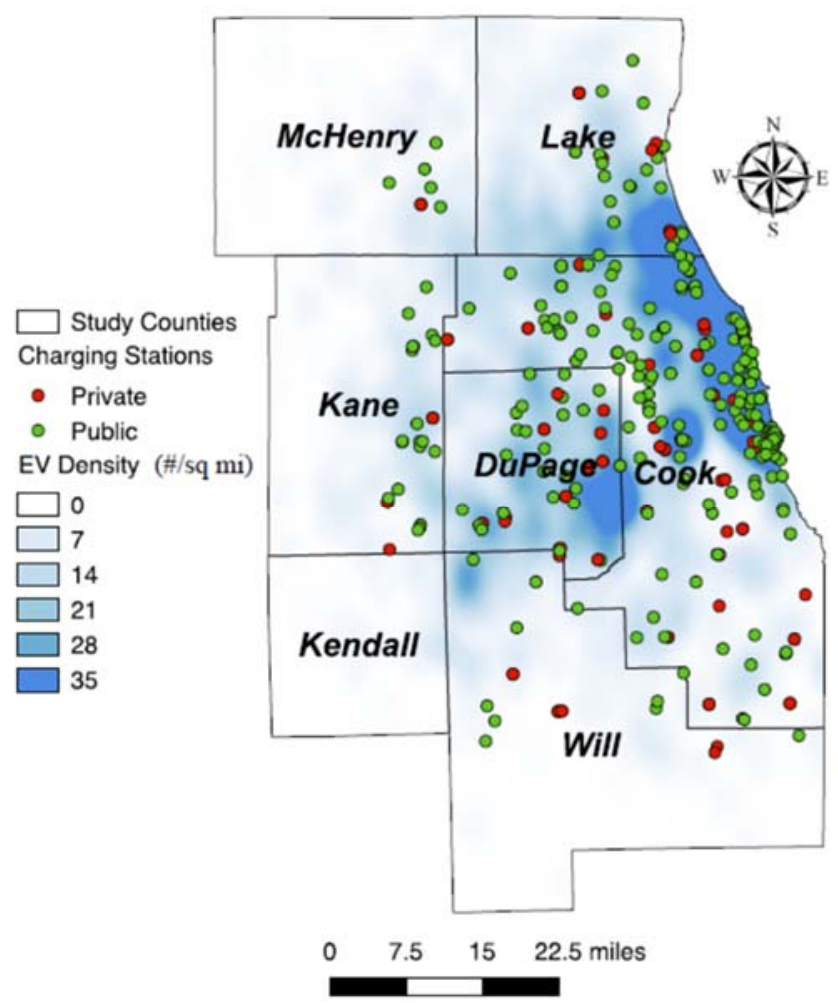

Figure 3.1 Density of BEVs and Charging Infrastructure in Study Area

(BEV density from IHS Markit as of Dec. 31, 2016; Charger locations from AFDC as of mid-2017)

\subsubsection{Projected growth}

EIA's forecast of total BEV registrations (Annual Energy Outlook 2017) provided the basis for our BEV forecast. Assuming that the study area accounts for a constant share of US registrations we estimate approximately 75,000 BEV registrations in 2030. Figure 3.2 shows the forecast. 


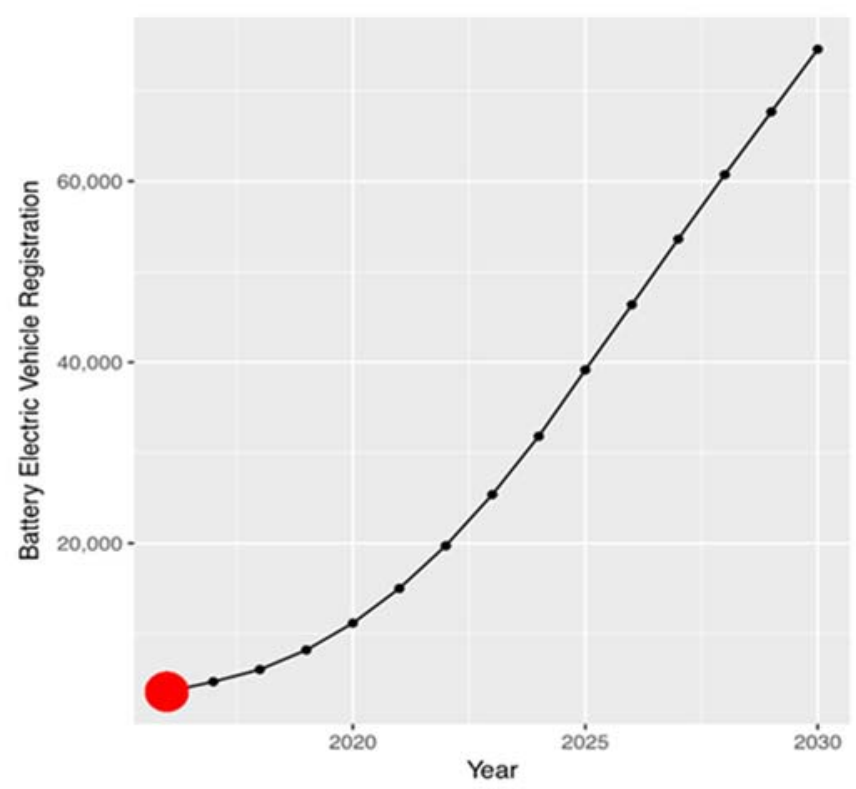

Figure 3.2 Estimated Chicago-Area BEV Registrations Based on U.S. BEV Registrations from EIA (2017) [1]

\subsection{Chargers and Charging Demand}

The locations of existing non-residential chargers were shown in Figure 3.1. The locations of future chargers are outputs of the simulation runs. These are discussed in Sections 4 and 6 . The following discussion summarizes charging demand as contained in the ChargePoint data set. Note that the raw data set includes all charging sessions for ChargePoint's 661 Chicago area stations from August 1, 2017 through July 31, 2018.

Although the ChargePoint data set does not represent all BEV charging in the study area and cannot be appropriately weighted to do so, it does permit us to identify patterns and gain important insights for the behavioral assumptions within ATEAM. Some of this work is complete; some is ongoing. We continue to examine spatial and temporal distributions of non-home charging sessions of the current stock of BEVs in order to reveal insights like times and locations of relatively higher power and energy demand, the relationship between active charging time and dwell time at the station, differences between observed and rated charging power, etc. While we believe many of these insights are behavioral, some may be technical (e.g., data collection/transmission errors). Thus, while we continue to investigate this issue, we note that our observations and initial conclusions related to the ChargePoint data are preliminary as of this writing.

\subsubsection{Spatial distribution of charging demand}

Figure 3.3 illustrates the spatial distribution of average hourly energy demand (in $\mathrm{kWh} / \mathrm{square}$ mile) for EV charging on the ChargePoint network. ${ }^{6}$ Note that areas with greater demand correspond to the areas of greater BEV density shown in Figure 3.1. In other words, along the lakefront, north from the Loop to southeastern Lake County, as well as pockets in Cook, DuPage, Lake and Will counties. There is

\footnotetext{
${ }^{6}$ The ChargePoint data set contains some charging episodes by plugin hybrids (PHEVs) in addition to BEVs.
} 
somewhat more demand in outlying area of Kane and Lake counties, presumably due to workplace charging.

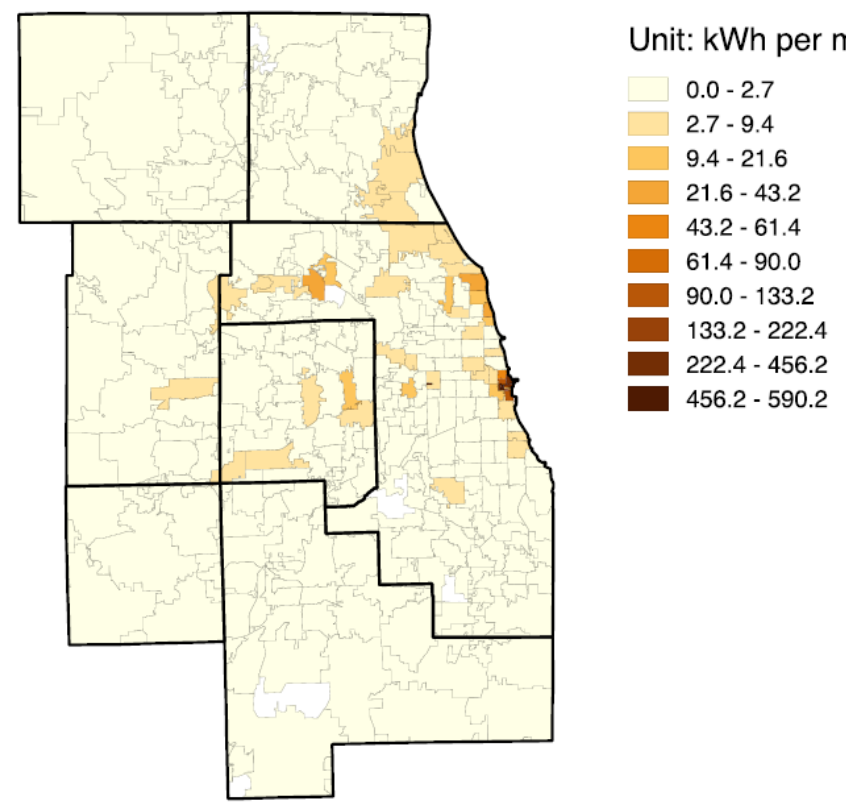

Figure 3.3 Average Hourly Energy Demand for BEV Charging, ChargePoint Data Set

\subsubsection{Temporal aspects of charging demand}

$\underline{\text { Hourly distribution }}$

Ignoring outliers, the ChargePoint data set includes over 142,000 sessions. As shown in Figure 3.4, the distribution of time at plug-in reveals a clear a.m. peak (between 6 and 9 a.m.) with a long tail into the late afternoon. Time at plug-off (Figure 3.5) is more variable, peaking at 3-6 p.m., with a secondary peak in the late morning. Because of the variety of host locations, this pattern likely reflects both workplace charging and "opportunity" charging at retail and business locations.

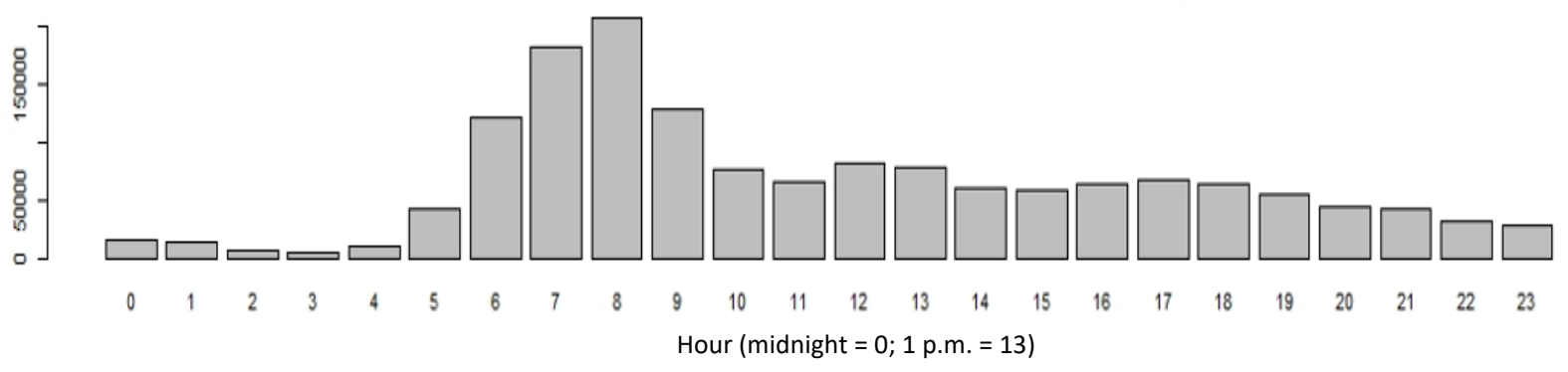

Figure 3.4 Session Plug-In Times for BEV Charging, ChargePoint Data Set 


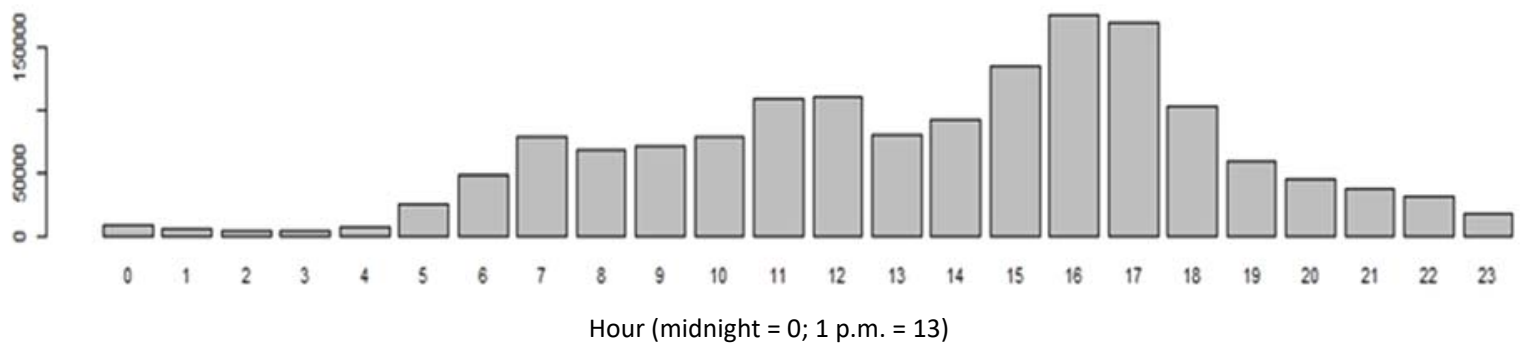

Figure 3.5 Session Plug-off Times for BEV Charging, ChargePoint Data Set

\section{Duration}

Excluding outliers, Figure 3.6 shows average charging time in minutes, the time vehicle was actively charging. While the average charging time is $100-150$ minutes, there is considerable variation. The skewed distribution suggests underlying differences between different types of stations (L2 vs. DC fast charge), as well as stations located in different settings (e.g., workplaces vs. business or retail establishments or chargers located in residential neighborhoods).

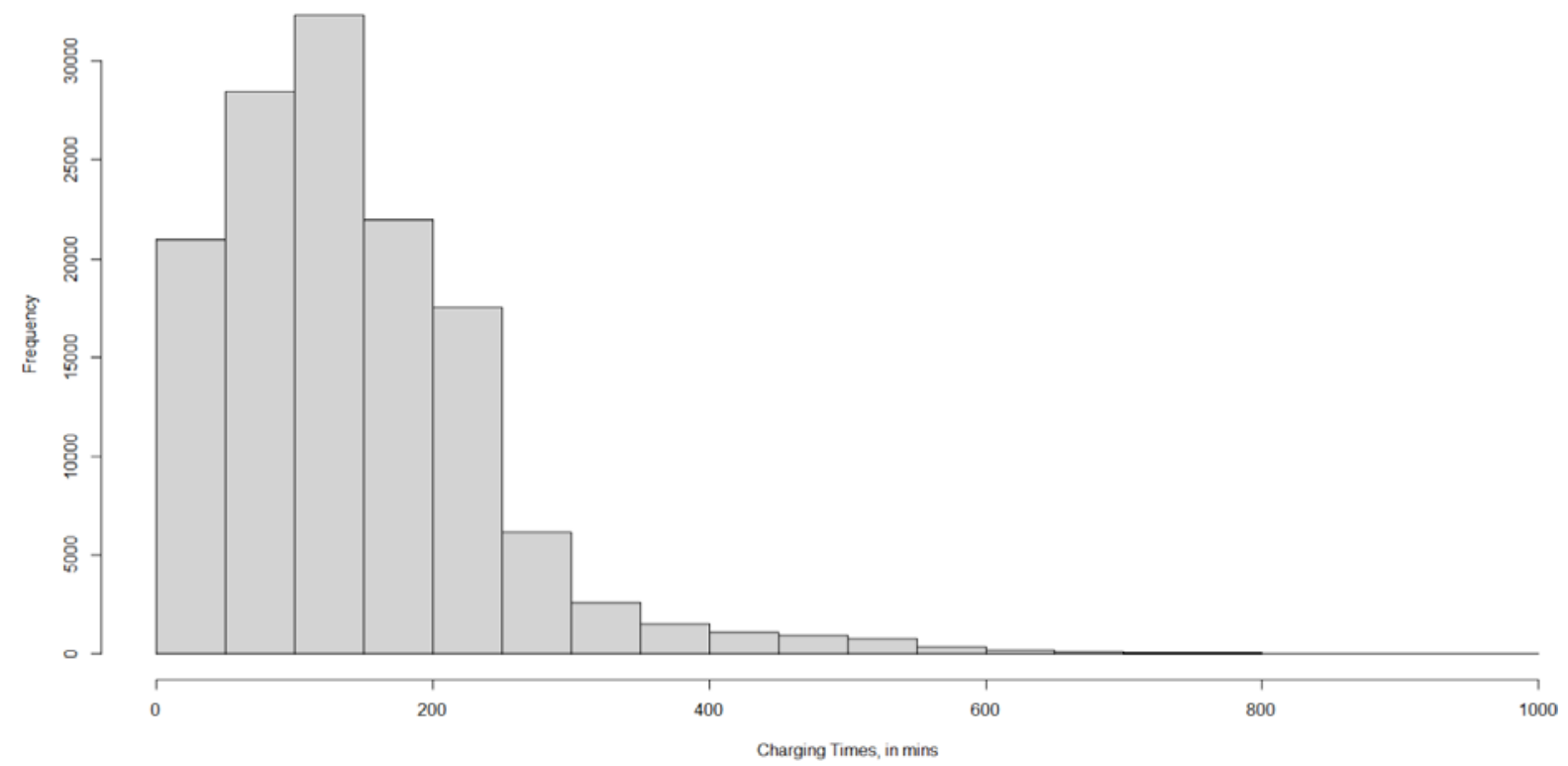

Figure 3.6 Average Charging Times, ChargePoint Data Set

\section{Dwell time at plug}

Measured as time between plug-in and plug-off, dwell time can be highly variable and can include significant time during which the BEV is not actually drawing power. Figure 3.7 shows the distribution of dwell time, both broken down into 50-minute segments (upper graph) and for the first hour of plug-in. Note that the distribution excludes charging episodes of less than two minutes since ChargePoint indicates that those episodes are often "tests" or "demos", not true charging sessions. Note also that the distribution is bi-modal (like the distribution of charging time), suggesting that underlying differences may account for at least some of the observed variation. 


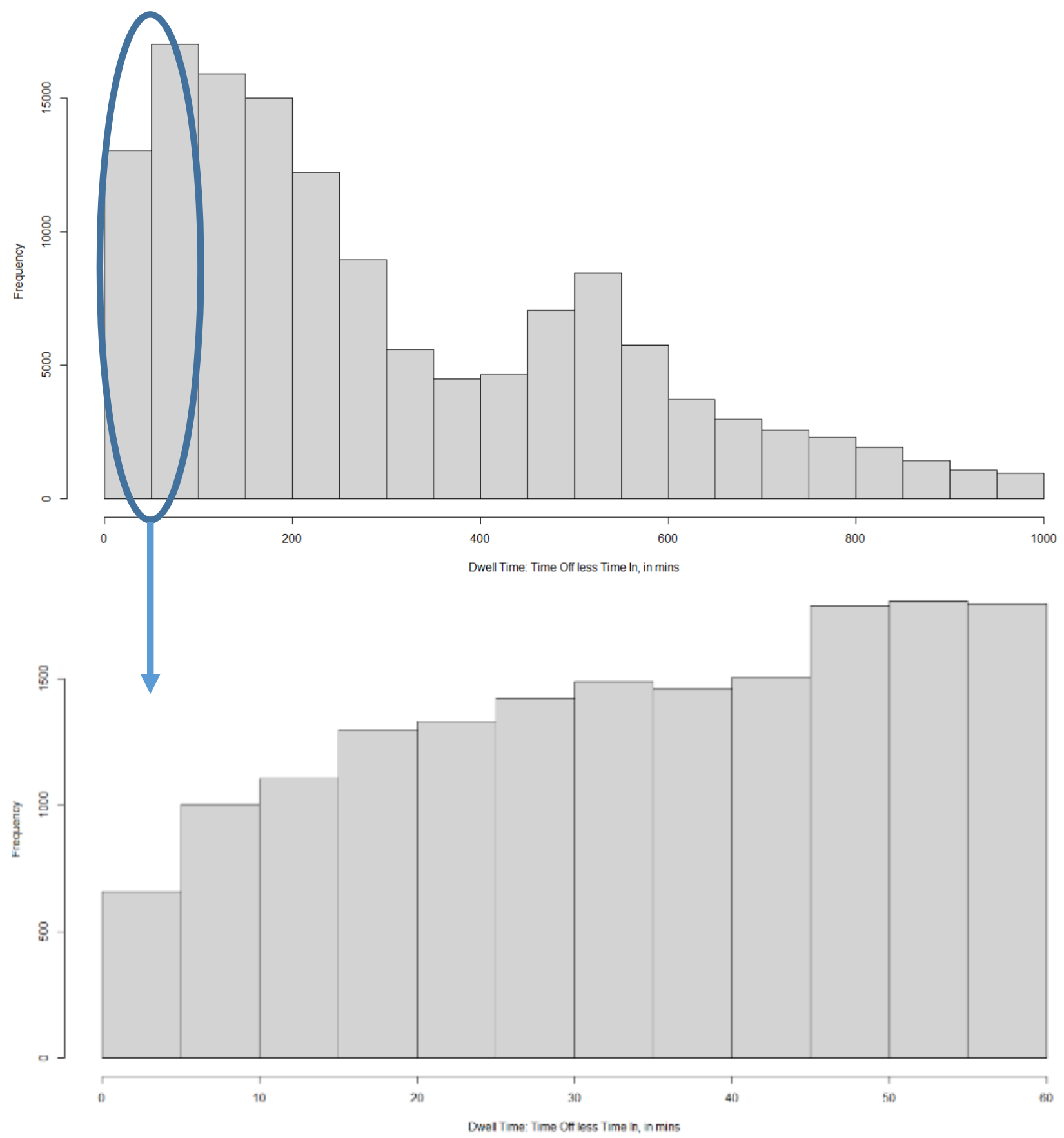

Figure 3.7 Dwell Times (0-1000 minutes and 0-60 minutes), ChargePoint Data Set

Given the time limitations of the ChargePoint data analysis, we have not been able to explore thoroughly the distributions of session time and dwell time. However, we note that the bimodal shape appears to be consistent across most charging station settings (including workplaces, commercial, utility and residential settings, and parking garages) as well as by charging levels.

\subsubsection{State of Charge (SOC) at plug-in and plug-off}

The ChargePoint data set includes 360 sessions with state-of-charge (SOC) reported at both plug-in and plug-off. All these sessions are at DC fast chargers (DCFCs) with a minimum plug-in time of 
two minutes or more. As shown in Figure 3.8 both distributions are skewed. Median SOC is $32.5 \%$ at plug-in; median SOC is $80.5 \%$ at plug-off. These values compare well with estimates from other studies.
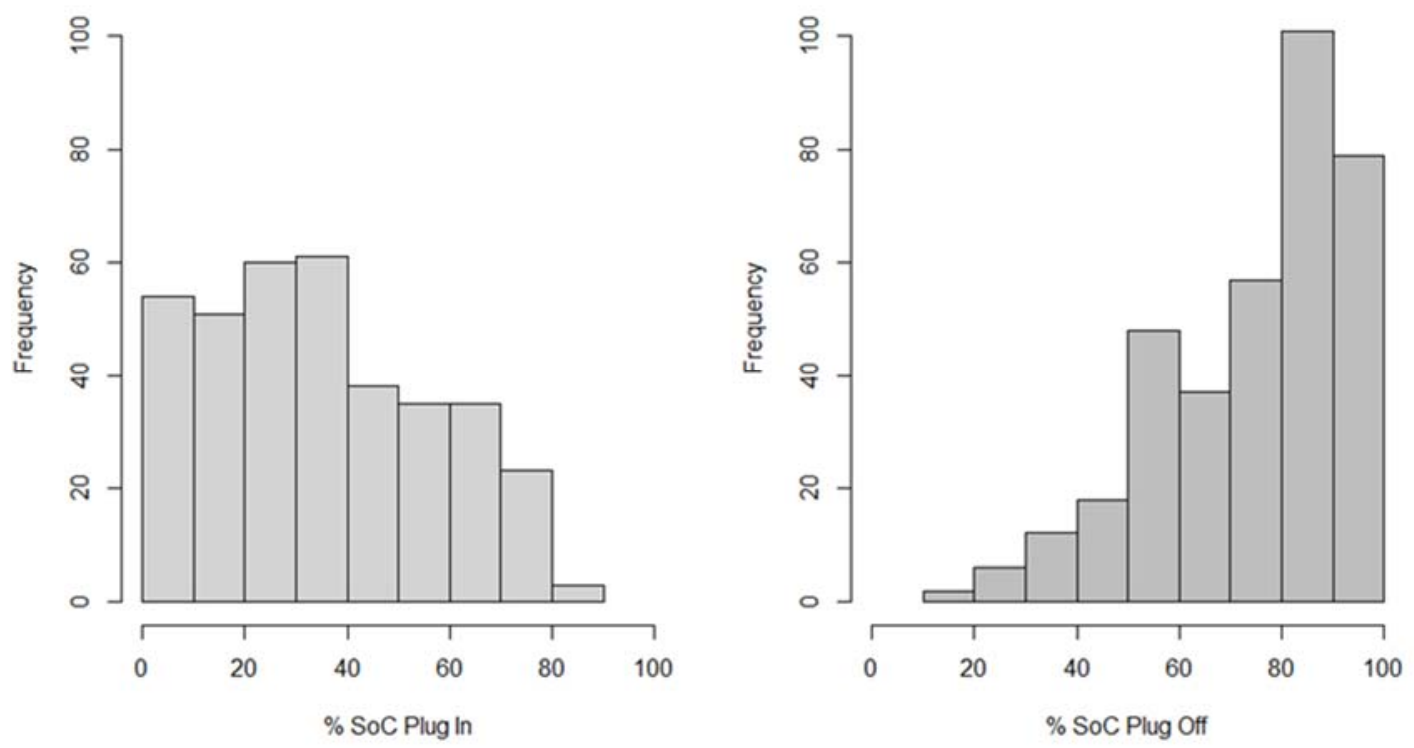

Figure 3.8 State-of-Charge at Plug-In and Plug-Off, ChargePoint Data Set

Figure 3.9 illustrates the change in SOC achieved by charging (i.e., SOC at plug-off less SOC at plug-in). The mean change is approximately $30 \%$ of SOC.

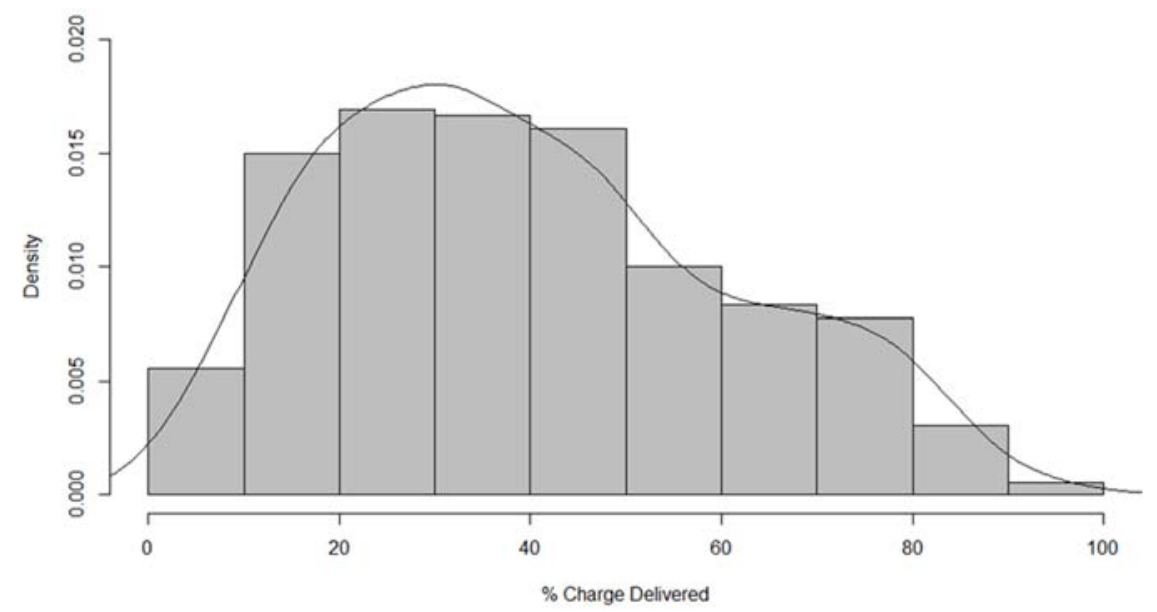

Figure 3.9 Change in SOC between Plug-In and Plug-Off, ChargePoint Data Set

\subsubsection{Average power}

Figure 3.10 and Figure 3.11 shows average power for vehicle charging across all sessions in the study area by hour. Note that zero corresponds to midnight. Because most ChargePoint stations are in commercial and workplace locations, average power is highest at around 9 a.m. Average power distributions for Cook, DuPage, Lake and Kane counties are similar in shape to this overall distribution. Much smaller distributions of average power for Will, Kendall and McHenry counties show a secondary peak in the evening hours. 


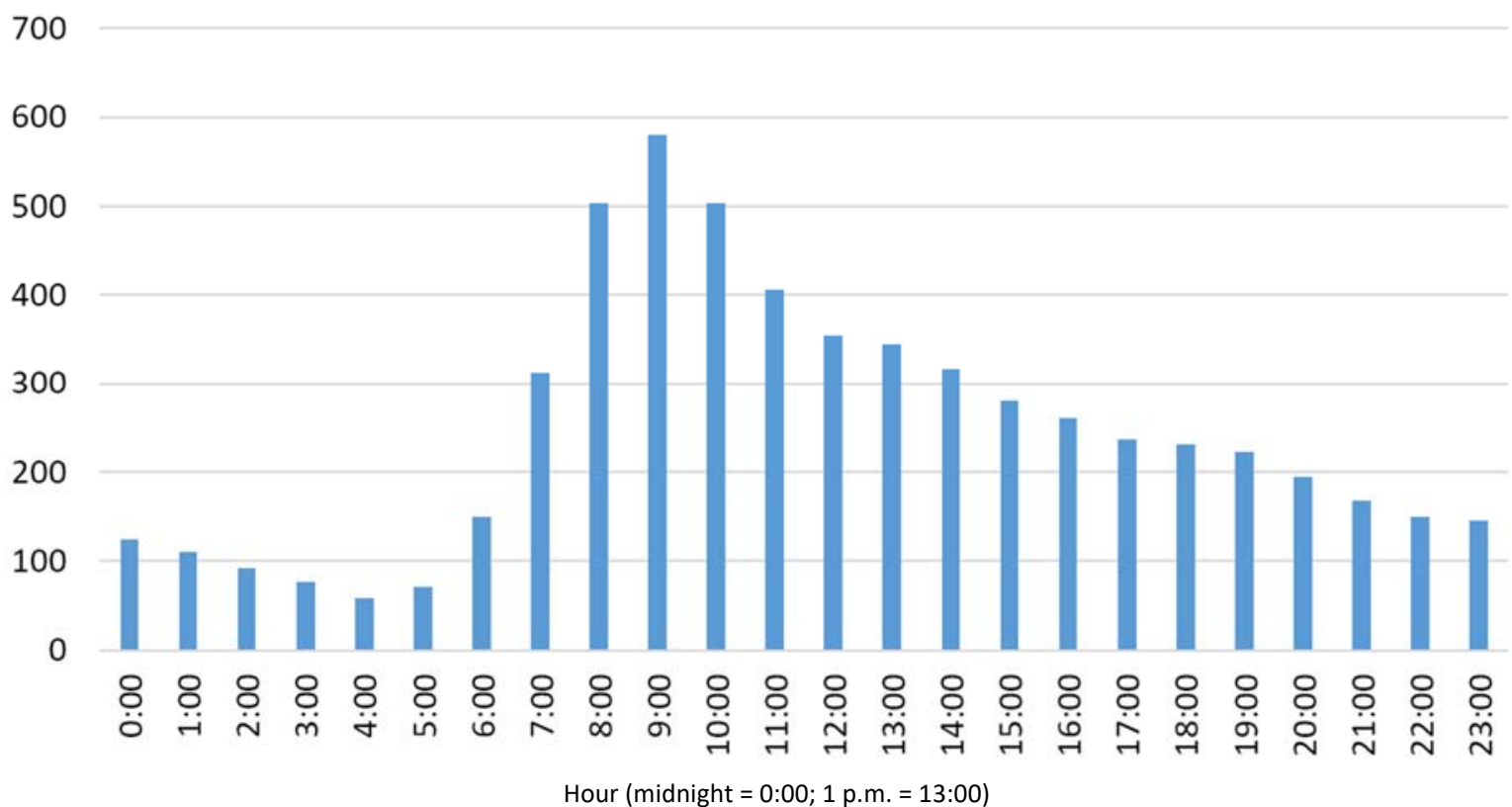

Figure 3.10 Average Power (in kW) for EV Charging in Study Area by Hour, ChargePoint Data Set 


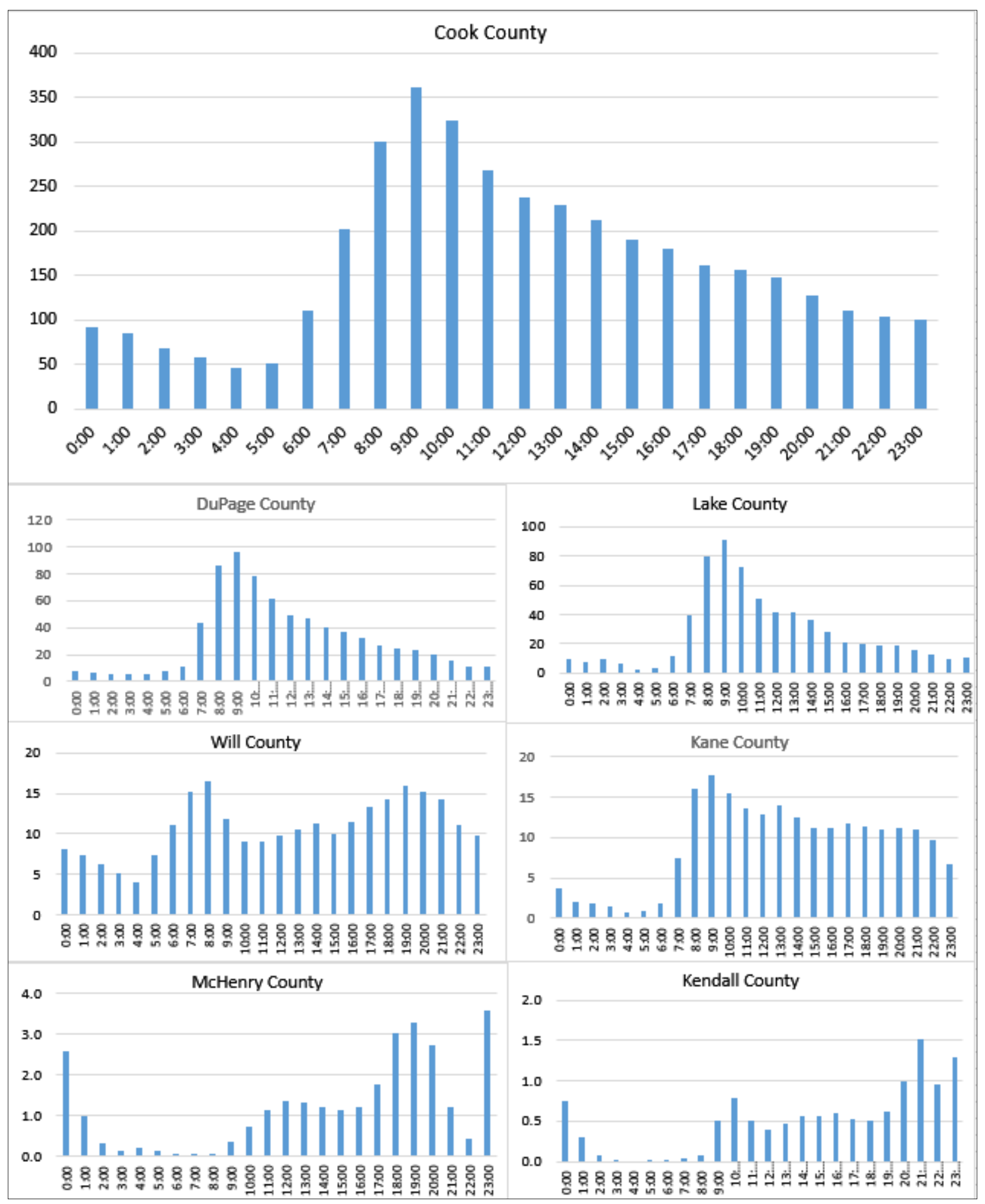

Hour (midnight $=0: 00 ; 1$ p.m. = 13:00)

Figure 3.11 Average Power (in MW) for EV Charging by Hour and County, ChargePoint Data Set 


\section{FUTURE DIRECTIONS}

This draft final report documents the development of ATEAM, an agent-based model of BEV charging demand and infrastructure expansion applied to the Chicago metropolitan area. The preliminary model results and initial analyses of 12 months of ChargePoint data have been reviewed by Exelon.

During the course of the project, the team discussed a number of other potential follow-on activities many of which could involve additions or expansions to the model. Validation is a particularly important next step, especially challenging for simulation models where outputs are the result of thousands of individual calculations.

In addition to model validation, potential follow-on activities include:

- Expanding household-agent decision-making to include BEV adoption

- Incorporating optimization to examine tradeoffs and differences between network- versus individually-sited stations

- Adding PHEVs and ride sharing/hailing options to driver-agent behavior

- Applying the model to other metropolitan areas (e.g., Baltimore)

- Coding and user interface improvements

- Expanding other household-, driver- and investor-agent decision models

The Argonne-Exelon team has successfully completed this project. The initial version of ATEAM is complete. ATEAM is installed on Argonne and Exelon laptop computers, and has been calibrated to observed charging behavior. ATEAM has been run to produce preliminary estimates of BEV charging demand. We are extending the model to the Baltimore-Washington D.C area and streamlining the simulation process to model large-scale BEV adoption in the next 10 years under this on-going collaboration between Argonne and Exelon. 


\section{REFERENCES}

1. Alternative Fuels Data Center, U.S. Department of Energy, Energy Efficiency \& Renewable Energy, https://afdc.energy.gov/.

2. Vehicle Market Analysis: Registrations and Vehicles-in-Operation, IHS Market, https://ihsmarkit.com/products/automotive-market-data-analysis.html.

3. My Daily Travel Survey, Chicago Metropolitan Agency for Planning, https://www.cmap.illinois.gov/data/transportation/travel-survey

4. Charging usage data, ChargePoint, https://www.ChargePoint.com/.

5. Annual Energy Outlook 2018, U.S. Department of Energy, Energy Information Administration, https://www.eia.gov/outlooks/aeo/.

6. Collier N., Howe T and North M.: Onward and upward: The transition to Repast 2.0. In Proceedings of the first annual North American AsSOCiation for Computational SOCial and Organizational Science conference. Edited by: Carley K. Carnegie Mellon University, Pittsburgh; 2003. Electronic Proceedings Electronic Proceedings.

7. Mahalik, M., M. Mintz and Z. Guo. Agent-Based Modeling of Consumer Behavior, Fuel Cell Technologies Office Annual Merit Review, Washington, DC, June 2017, Available at https://www.hydrogen.energy.gov/pdfs/review17/sa065_mintz_2017_o.pdf.

8. VISION Model, Argonne National Laboratory, 2018, https://www.anl.gov/es/vision-model.

9. Jin, L., Searle, S., and Lutsey, N. (2014). Evaluation of state-level U.S. PEV incentives. International Council on Clean Transportation. http://www.theicct.org/sites/default/files/publications/ICCT_state-EV-incentives_20141030.pdf

10. Narassimhan, E., and Johnson, C. (2014). The effect of state incentives on plug-in PEV purchases. National Renewable Energy Laboratory. Presentation to DOE. http://www.nrel.gov/docs/gen/fy15/62884.pdf

11. Lutsey, N., Searle, S., Chambliss, S., and Bandivadekar, A. (2015). Assessment of leading PEV promotion activities in United States cities. International Council on Clean Transportation. http://www.theicct.org/sites/default/files/publications/ICCT_EV-promotion-UScities_20150729.pdf

12. Vergis, S., and Chen, B. (2015). Comparison of plug-in electric vehicle adoption in the United States: A state-by-state approach, Research in Transportation Economics, 52 (2015), 56-64.

13. Zhou, Y., Santini, D., Vazquez, K., and Rood, M., Contributing factors in plug-in electric vehicle adoption in the United States: A Metro/County Level Approach, proceedings of 96th Transportation Research Board Annual Meeting, 2017.

14. Springel K. Network Externality and Subsidy Structure in Two-Sided Markets: Evidence from Electric Vehicle Incentives. 2016.

15. Lin Z. Optimizing and Diversifying Electric Vehicle Driving Range for U.S. Drivers. Transportation Science, 48(4):635-50, 2014.

16. Levinson RS, West TH. Impact of public electric vehicle charging infrastructure. Transportation Research Part D: Transport and Environment. 2017.

17. California Clean Vehicle Rebate program, https://cleanvehiclerebate.org/eng/surveydashboard/ev 
18. Update: California's electric vehicle market, May 2017, https://www.theicct.org/sites/default/files/publications/CA-cities-EVupdate ICCT Briefing 30052017 vF.pdf

19. Tal, G., Plug-In Electric Vehicle Multi-State Market and Charging Survey. EPRI, Palo Alto, CA. 3002007495, 2016.

20. Fanchao Liao, Eric Molin \& Bert van Wee, Consumer preferences for electric vehicles: a literature review, Transport Reviews, Volume 37, 2017.

21. Axsen, J., Bailey, J., Castrob, M.A., Energy Economics, Volume 50, July 2015, Pages 190-201, https://doi.org/10.1016/j.eneco.2015.05.003Preference and lifestyle heterogeneity among potential plug-in electric vehicle buyers.

22. Gil Tal, Dillon T. Fitch and Michael A. Nicholas, Modeling the Spatial Distribution of Plug-In Electric Vehicle Owners in California: A GIS Scenario Planning Tool, UCD-ITS-WP-14-06, 2014.

23. Plugged In: How Americans Charge Their Electric Vehicles, Idaho National Laboratory, INL/EXT15-35584, 2015.

24. Evaluating Electric Vehicle Charging Impacts and Customer Charging Behaviors: Experiences from Six Smart Grid Investment Grant, U.S. Department of Energy, Electricity Delivery \& Energy Reliability.

25. Kuby M, Lim S. The flow-refueling location problem for alternative-fuel vehicles. SOCioEconomic Planning Sciences. 39(2):125-45, 2005.

26. Lin Z, Greene DL. Promoting the Market for Plug-In Hybrid and Battery Electric Vehicles: Role of Recharge Availability. Transport Res Rec. 2011;2252(1):49-56.

27. He F, Yin Y, Zhou J. Deploying public charging stations for electric vehicles on urban road networks. Transportation Research Part C: Emerging Technologies. 2015; 60:227-40.

28. Xie F, Liu C, Li S, Lin Z, Huang Y. Long-term strategic planning of inter-city fast charging infrastructure for battery electric vehicles. Transportation Research Part E: Logistics and Transportation Review. 2018;109:261-76.

29. Wood E, Raghavan S, Rames C, Eichman J, Melaina M. Regional Charging Infrastructure for PlugIn Electric Vehicles: A Case Study of Massachusetts National Renewable Energy Laboratory; 2017.

30. Liu C, Lin Z, Kontou E, Wu X. Value of public charging: understanding the linkage between charging network coverage and charging opportunity using multi-city GPS travel data. Transportation Research Part C, under revision (to be published), 2018.

31. 2017 National Household Travel Survey, U.S. Department of Transportation, Federal Highway Administration, 2018.

32. AIAA (American Institute of Aeronautics and Astronautics), 1998, Guide for the Verification and Validation of Computational Fluid Dynamics Simulations, American Institute of Aeronautics and Astronautics, Reston, VA, AIAA G-077-1998, Jan. 14, 1998.

33. Roache, P. J., 1998, Verification and Validation in Computational Science and Engineering, Hermosa Publishers: Albuquerque, NM.

34. Balci, O., 1998, Chapter 10: Verification, Validation, and Testing, in Handbook of Simulation, Banks, J., (ed.) pp. 335-393, New York: John Wiley, Date.

35. Bankes, S. C., 1993, Exploratory Modeling for Policy Analysis, Operations Research 41(3):435449.

36. Law, A. M., 2007, Simulation Modeling \& Analysis, Boston: McGraw-Hill, 4th edition. 
37. Sargent, R. G., 2003, Verification and Validation of Simulation Models, Proc. 2003 Winter Simulation Conference, S. Chick, P.J. Sanchez, D. Ferrin, and D.J. Morricepp (eds.), 37-43.

38. Popper, K. R., 1959, The Logic of Scientific Discovery, New York: Basic Books.

39. Boero, Riccardo and Flaminio Squazzoni. "Does Empirical Embeddedness Matter? Methodological Issues on Agent-Based Models for Analytical Social Science." October 31, 2005. http://jasss.soc.surrey.ac.uk/8/4/6.html.

40. Moss, Scott, and Bruce Edmonds. "Sociology and Simulation: Statistical and Qualitative CrossValidation." The American Journal of Sociology 110, no. 4 (January 2005): 1095.

41. Hales, David, Juliette Rouchier, and Bruce Edmonds. "Model-to-Model Analysis." October 31, 2003. http://jasss.SOC.surrey.ac.uk/6/4/5.html.

42. Sallans, Brian, Alexander Pfister, Alexandros Karatzoglou, and Georg Dorffner. "Simulation and Validation of an Integrated Markets Model." October 31, 2003. http://jasss.SOC.surrey.ac.uk/6/4/2.html.

43. Lempert, R. J., S. W. Popper and S. C. Bankes, 2003, Shaping the Next One Hundred Years: New Methods for Quantitative Long-Term Policy Analysis, Santa Monica, CA: RAND, pp. 187. 
Agent-Based Transportation Energy Analysis Model: Methodology and Initial Results 



\section{Argonne}

\section{Energy Systems Division}

Argonne National Laboratory

9700 South Cass Avenue, Bldg. 362

Lemont, IL 60439

www.anl.gov 